\title{
Metal-Organic Frameworks-Based Catalysts for Biomass Processing
}

\author{
Vera I. Isaeva ${ }^{1,2, *}$, Oleg M. Nefedov ${ }^{1}$ and Leonid M. Kustov ${ }^{1,2}$ \\ 1 N.D. Zelinsky Institute of Organic Chemistry, Russian Academy of Sciences, Leninsky Prospect 47, \\ 119991 Moscow, Russia; svitanko@mail.ru (O.M.N.); LMK@ioc.ac.ru (L.M.K.) \\ 2 National University of Science and Technology "MISiS", Leninsky Prospect, 4, 119991 Moscow, Russia \\ * Correspondence: sharf@ioc.ac.ru; Tel./Fax: +7-499-1372-935
}

Received: 5 August 2018; Accepted: 21 August 2018; Published: 31 August 2018

\begin{abstract}
Currently, metal-organic frame works (MOFs) as novel hybrid nanoporous materials are a top research interest, including endeavors in heterogeneous catalysis. MOF materials are promising heterogeneous catalytic systems due to their unique characteristics, such as a highly ordered structure, a record high surface area and a compositional diversity, which can be precisely tailored. Very recently, these metal-organic matrices have been proven as promising catalysts for biomass conversion into value-added products. The relevant publications show that the structure of MOFs can contribute essentially to the advanced catalytic performance in processes of biomass refining. This review aims at the consideration of the different ways for the rational design of MOF catalysts for biomass processing. The particular characteristics and peculiarities of the behavior of different MOF based catalytic systems including hybrid nanomaterials and composites will be also discussed by illustrating their outstanding performance with appropriate examples relevant to biomass catalytic processing.
\end{abstract}

Keywords: biomass valorization; value-added products; heterogeneous catalysis; hybrid materials; metal-organic frameworks (MOFs)

\section{Introduction}

In modern industrial society, non-renewable fossil fuels such as petroleum, coal and natural gas is a worldwide source of the energy and with the rapid technology development their reserves decrease with an exponentially growing rate [1]. In addition, the non-renewable fossil fuels supply the industrial processes relevant to the production of a large diversity of chemicals [2]. This concern is a stimulus for the search for new sustainable and efficient alternate sustainable feedstocks instead of non-renewable sources. In recent decades, the biomass has become a candidate No. 1 in this respect that can be converted through bio-refinery and catalytic valorization into liquid fuels, value-added chemicals and new bio-based materials such as bioplastics [3].

The transformation of biomass to chemicals and fuels can be generally realized by three different techniques: thermal, biochemical and chemical routes. Thermal techniques, like pyrolysis and gasification, can take full advantage of the entire organic substance of this resource. However, this pathway features a low selectivity and high energy input. On the contrary, bioconversion or fermentative conversion of biomass is characterized by good selectivity. An example is a fermentation of carbohydrates affording non-conventional energy sources like bio-ethanol and bio-gas as well as butanol and $\mathrm{CO}_{2}[1,4]$. However, bioconversion processes feature often a low efficiency. The most efficient route is the catalytic transformation of biomass into non-conventional fuels like bioethanol and biogas and highly valuable chemicals. The necessary requirements for this conversion are a moderate temperature regime, liquid phase combined with a high processes selectivity. A variety of processes 
for the production of green chemicals derived from biomass have been developed in the last few years [3,5].

In this context, catalysis provides efficient tools for converting and upgrading biomass into highly demanding products. It is important to note in this respect that the heterogeneous catalytic processes obey the principles of green chemistry with the result of a significant reduction of wastes [6].

The catalytic conversion of biomass and derivatives to chemicals has been the subject of intensive research efforts during the past decade. A relatively large number of reviews are focused on specific biomass feedstocks such as carbohydrates [5,7], triglycerides [8], glycerol [9], 5-hydroxymethylfurfural, cellulose, hemicelluloses and pentoses, polyols like mannitol and sorbitols, lignin and lignocellulose. Some reviews were dedicated to specific reaction types such as hydrogenation, hydrogenolysis/dehydroxylation, telomerization, metathesis and oxidation [10]. These review articles consider the important issues relating to the choice of starting feedstocks along with peculiarities in their biorefinery processing and the best way to obtain the target chemicals [11]. The available literature data show that the development of new synthetic routes for catalytic processes for transformation of biomass into known bio-based products or new building blocks and materials has a great impact.

The third category of reviews (relatively few) related to this topic (to which belongs this review) deals with particular catalytic system types, including metal catalysts [12] by highlighting their specific characteristics and advantages/disadvantages or comparing different catalysts with each other (MOFs and zeolites) in order to evaluate and develop cost-effective catalytic processes adapted to the molecular structure of highly functionalized biomass molecules [13].

Numerous solid catalytic systems for the effective conversion of biomass feedstocks into value-added chemicals and fuels have been developed. Solid catalysts exploited for biomass upgrading can be classified into four main groups: (a) micro- and mesoporous materials, (b) metal oxides, (c) supported metal catalysts and (d) sulfonated polymers [12,14]. As to metal-based catalysts, many reviews describe conversion of biomass to biofuels, comparatively less attention has been paid to catalysts adapted to the biomass-to-chemical-value chain [12].

High surface acidity and porous nanostructures (large surface area) of the nanomaterials play crucial role in these heterogeneous catalytic processes. Accordingly, several nanoporous solid acid catalysts such as porous resins, micro/mesoporous carbons, micro-/mesoporous zeolites, mesoporous metal oxides, functionalized mesoporous silicas and porous organic polymers are successfully employed in selective biomass conversion reactions [1].

In addition to nanoporosity, bifunctionality is another important feature of the efficient catalysts designed for biomass processing. Commonly, the biomass conversion process comprises a series of cascade reactions [15]. Therefore, the efficient catalytic system has to possess bifunctional properties like Brønsted-Lewis acidic, acidic-basic and metal nanoparticles-acidic or basic ones to accomplish these transformations. Accordingly, bifunctional catalytic materials are used now in one-pot multiple transformations of biomass into biofuels and related chemicals [16]. An example is the use of appropriate bifunctional catalysts that simplify processing of lignocellulosic biomass for producing biofuels and chemicals. The advanced performance of the bifunctional catalysts like metal phosphonates and relatively novel catalytic nanomaterials-metal-organic frameworks (MOFs) is compared to those of the conventional solid acid catalysts in [1].

Thus, the literature reports that the ideal catalyst for biomass should be highly porous and bifunctional. The modern class of the hybrid nanoporous inorganic-organic materials-MOFs are now among the currently most studied solids in heterogeneous catalysis [17-22]. They almost fully fit these requirements thanks to their intrinsic compositional, structural and physicochemical properties, which can be rationally designed. Essential in the context of design of the advanced catalytic system for biomass upgrading, MOFs are an ideal platform for preparation of functional materials on their basis, including MOFs-based and MOFs-derived composites or hybrid materials, which can also show the enhanced intrinsic catalytic behavior in the considered processes. 
The scope of the review is to justify the opinion (pro and contra) that namely MOFs are the most promising catalytic materials for biomass valorization and upgrading for the preparation of valuable chemicals and biofuel. We intend to consider the specific features of catalytic MOFs-materials and MOFs-derived hybrids and illustrate their performance by appropriate (best and most illustrative) examples relevant to biomass catalytic processing, including synthesis and conversion of glycerol and glycerides, 5-hydroxymethylfurfural, polyols, carbohydrates as well as lignocellulosics. The specific characteristics of the MOF based materials will be also discussed.

\section{MOFs-Based Catalysts and Their Main Characteristics}

In this section, we will analyze briefly the characteristic features of MOF materials relevant to the sustainable catalysis of the biomass conversion.

Metal-organic frameworks (MOFs) are an important class of relatively new hybrid materials in the vast field of metal organic materials (MOMs) $[6,23,24]$. These inorganic-organic materials MOFs are porous coordination polymers constructed from inorganic nodes (metal ions or clusters) coordinated with multi-topic organic bridging linkers through strong bonds to form three-dimensional (3D) coordination networks $[25,26]$. Over past two decades, they capture an increased attention of the worldwide researcher community due to their outstanding properties [27]. The crystalline nature with a low crystal density (up to $0.13 \mathrm{~g} \mathrm{~cm}^{-3}$ ), ultrahigh surface area (up to $10400 \mathrm{~m}^{2} \mathrm{~g}^{-1}$ ), a large pore aperture (up to $98 \AA$ ), structural diversity as well as tailored pore functionality make MOFs the promising functional materials with potential applications in diverse fields, such as gas sorption and separation, chemical sensing, proton conductivity, biomedicine and so forth [28]. In particular, heterogeneous catalysis is one of the most important applications for MOFs [29]. The open porous system and high porosity and large inner surface area of MOFs allow fast mass transport and/or interactions with substrates [6,30]. The efficiency of MOF catalytic materials in shape- and size-selective and regio- and enantioselective reactions can be realized due to unique active site structures and adjusted micro/meso porosity of a number of the metal-organic frameworks [31,32]. MOF-based catalysts can have active sites both in inorganic nodes (metal centers) and organic linkers [33]. Especially, the organic bridging linkers may be used as scaffolds to which distinct catalytic complexes, bio-molecules and homogeneous catalysts can be immobilized or encapsulated.

MOF catalysts exhibit the following distinct traits: (i) uniformly dispersed catalytic sites on the pore surface, which contributes to selectivity; (ii) appropriate hydrophilic and hydrophobic pore nature to facilitate the recognition and transportation of reactant and product molecules; (iii) multifunctional microenvironment to realize synergistic catalysis; and (iv) simple separation and recovery for long-term usage [34]. The presence of metal coordination centers in MOF frameworks can promote a wide range of organic reactions [35], in particular, relevant to biomass conversion. Additionally, thanks to the versatility of synthesis and their structural and compositional diversity MOFs have a reputation of eco-friendly alternatives for catalysis [36].

However, the full realization of the potential of these catalytic materials is limited often by a deficiency of functional sites in the MOF frameworks [37]. The adequate solution of this problem is fine tuning of the MOF structures and porosity for a specific catalytic process. Among the possible routes to introduce the supplementary active sizes in MOF host matrices, one can use the direct synthesis by careful choice of organic and inorganic building blocks or their post-synthetic functionalization (PSM) [38], grafting of active groups on the open metal sites [39] and encapsulation of active species like metal and metal oxide nanoparticles as well as small molecules (active homogeneous catalysts) in the pore voids [26,40-42]. The diversity of the modification routes distinguishes MOFs from other nanoporous materials such as zeolites and activated carbons.

MOFs are compared very often with zeolites that is, another type of highly ordered nanoporous materials. To date, zeolites have been used as heterogeneous catalysts in many industrial processes $[43,44]$. However, these materials exhibit limitations for the manufacturing of bulky and high value added organic molecules due to the small pore size of zeolite channels and cavities. 
Multi-functionality, high porosity, tenability and original flexibility are placing MOF materials at the frontier between zeolites and enzymes [45,46]. However, in most cases, MOFs show a good thermal stability $\left(400-500{ }^{\circ} \mathrm{C}\right.$ ) but not a bit approaching the stability of zeolites (as high as $\sim 700^{\circ} \mathrm{C}$.

As it was mentioned above, in terms of catalytic biomass valorization, a very large number of MOF materials have a great potential due to their high porosity and compositional versatility. The particular property of MOFs is that their bifunctionality, or rather multifunctionality comprises the possession of active sizes of different sorts on and in their porous matrices. Bifunctional MOFs containing unsaturated metal centers and metal NPs or organic linkers with Lewis/Brønsted acidic/basic sites are used as solid catalysts in organic transformations [6,35]. Some multi-functional MOFs have been also developed and demonstrate an enhanced performance in different organic reactions including transformations relevant to the biomass processing [13].

Thus, the structure of MOFs is highly attributed to the catalytic activity and selectivity in processes of biomass refining. Accordingly, we intend to highlight structure-activity/selectivity correlation in this review.

\section{Rational Design of MOF Catalysts for Biomass Valorization}

Mainly, the available excellent reviews related to the MOF application in biomass valorization highlight the processes and reactions $[13,21,36]$. On the contrary, we are attempting to focus on the MOF materials essential properties and approaches to their design, which involve the versatile hybrid nature of highly porous metal-organic frameworks: a careful choice of organic and inorganic building blocks, control of the size of MOF catalyst materials in the nanoscale range, post-synthesis modification of inorganic nodes and organic linkers, encapsulation of functionalities (catalytically active molecules and species) in MOF host matrices, preparation of MOFs-based composites and MOFs-derived materials.

In the next section, we present the ways for the rational design of MOF structures with illustration by the relevant catalytic processes. The most representative process from this point of view is carbohydrate depolymerization, resulting in the formation of platform compounds. This reaction is an efficient strategy in order to obtain the value-added chemicals and bio-fuels, such as methyl lactate, levulinic acid, hydroxymethylfurfural (HMF), furfural and so forth. As a rule, these transformations demand for the presence of acidic active sites, because the reaction pool comprises dehydration, isomerization, esterification as well as cascade reactions involving these reactions. In this process, all features or possibilities of MOF structures can be involved.

Practical routes to introduce the appropriate catalytic functionalities needed for efficient biomass valorization include direct synthesis or post-synthetic modification [47], grafting of active groups on the open metal sites of certain structures [48] and encapsulation of active species [49,50]. However, a simpler strategy involving a judicious selection of MOF structures with desired active sites in their building blocks, inorganic nodes and organic linkers allows one to obtain sometimes good catalytic results.

\subsection{Evaluation of Appropriate MOF Structures Relevant to Biomass Valorization}

An appropriate choice of the parent (precursor) MOF structure is a first step in this engineering of the MOFs-based catalysts. Generally speaking, there are some popular MOF materials that are most frequently used as heterogeneous catalysts [34]. Moreover, the overwhelming number of publications relevant to biomass valorization discussed a catalytic performance of these MOF structures, which are, first of all, HKUST-1, MIL-101(Cr), UiO-66 and UiO-67 (amino-modified analog of the UiO-66 analog) frameworks [13]. Their structures have coordinatively-unsaturated (open) sites with Lewis acidity in inorganic nodes (metal ions) in the networks. These Lewis acid sites as structure constituent elements are of paramount importance for cascade processes of catalytic biomass valorization (involving depolymerization, dehydration and isomerization).

The first MOF structure, which is preferred as a biomass upgrading catalyst is the MIL-101(Cr) $\left(\mathrm{Cr}_{3}(\mathrm{~F}) \mathrm{O}(\mathrm{BDC})_{3}, \mathrm{BDC}=1\right.$,4-benzenedicarboxylate) framework [51]. It has two types of zeotypic 
mesoporous pores (Figure 1) with free diameters of $\sim 2.9$ and $3.4 \mathrm{~nm}$, respectively, accessible through two microporous windows of $\sim 1.2$ and $1.6 \mathrm{~nm}$. The MIL-101(Cr) framework has a very high specific surface area of $4100 \mathrm{~m}^{2} \mathrm{~g}^{-1}$ (BET). On the other hand, this framework contains unsaturated (open metal) sites $\left(\mathrm{Cr}^{3+}\right.$, up to $\left.3 \mathrm{mmol} \mathrm{g}^{-1}\right)$ in which solvent or substrate molecules can be adsorbed. These unsaturated coordination positions can be used as Lewis acid sites in many organic transformations. The MIL-101(Cr) material is thermally stable up to $275^{\circ} \mathrm{C}$ (air), which allows its application for a wide range of catalytic reactions. For this reason, the MIL-101(Cr) structure is one of the most studied MOF catalysts for biomass upgrading [52].

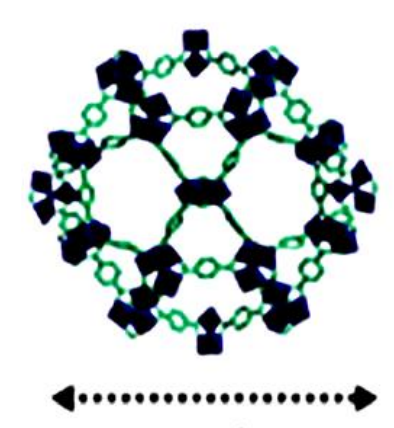

29A

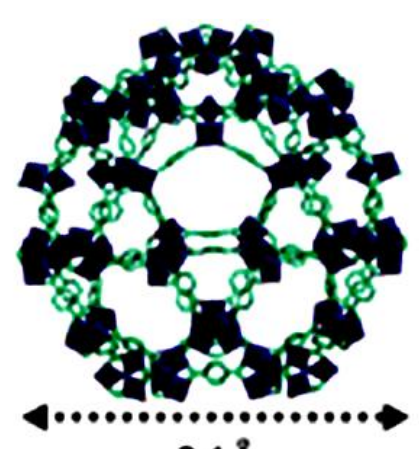

$34 \AA$

Figure 1. Two types of cages present in the structure of MIL-101(Cr). Reprinted with permission from reference [34]. Copyright 2017 Royal Society of Chemistry.

HKUST-1 $\left(\mathrm{Cu}_{3}(\mathrm{BTC})_{2}\right.$, BTC = benzene-1,3,5-tricarboxylate $)$ is another metal-organic framework extensively studied as a catalyst for biomass valorization (Figure 2). It is one of the most known MOF compounds with a long history due to its interesting structure and adsorption characteristics and open metal sites $\left(\mathrm{Cu}^{2+}\right)$ with Lewis acidity, which are potential active centers $[53,54]$. Noteworthy, the concentration of these open Lewis centers in the HKUST-1 framework is high thereby they can contribute in particular improvement of the catalytic activity [55]. To date, a number of studies reported an important catalytic behavior of $\left[\mathrm{Cu}_{3}(\mathrm{BTC})_{2}\right]$, highlighting its potential as a promising acidic heterogeneous catalyst for the production of fine chemicals, including value-added products of biomass-upgrading [56] due to Lewis acid sites located at the inorganic nodes and Brønsted acid sites situated in 1,3,5-benzenetricarboxylate linkers.

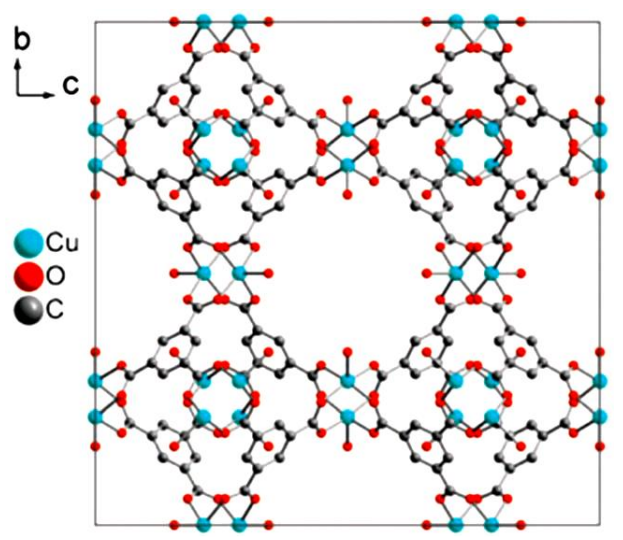

Figure 2. View of the packing of the cubic unit cell of HKUST-1. Reprinted with permission from reference [34]. Copyright 2017 Royal Society of Chemistry. 
The third MOF structure evaluated for heterogeneous catalysis is the UiO-66( $\mathrm{Zr})$ framework based on BDC linkers and its isostructural analogue, UiO-67( $\mathrm{Zr}$ ) based on the 4,4'-biphenyldicarboxylate (BPDC) linker (Figure 3) [57]. The UiO-66(Zr) and UiO-67(Zr) metal-organic frameworks are studied for different application fields due to their exceptional thermal and chemical stability [58].

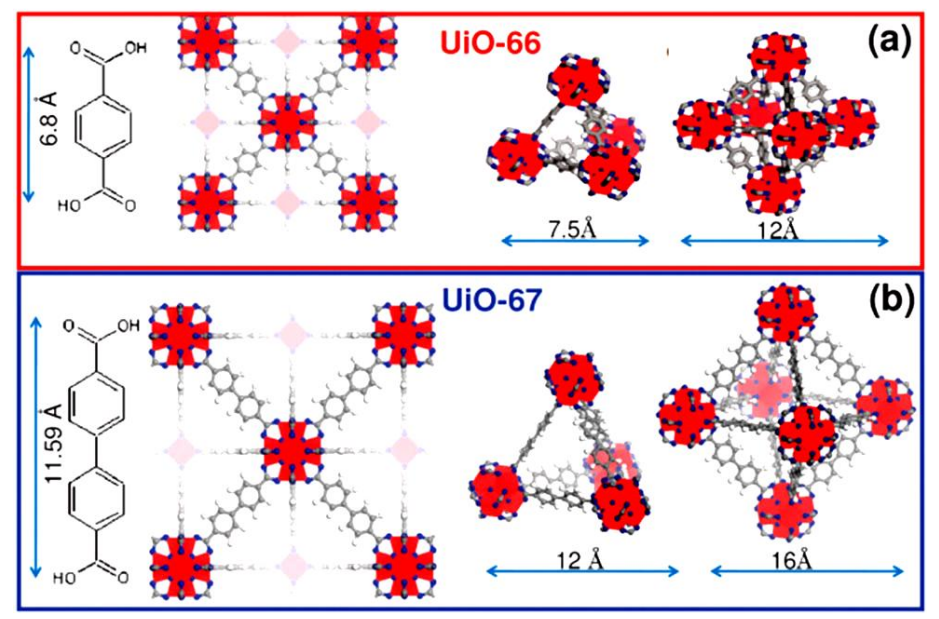

Figure 3. Structures of UiO-66 (a) and UiO-67 (b). Reprinted with permission from reference [34]. Copyright 2017 Royal Society of Chemistry.

The importance of open metal sites (coordinatively unsaturated sites) for catalytic activity of MOF materials should be especially emphasized. In many cases, the Lewis acid character of the metal-organic frameworks is derived from the creation of a coordination vacancy upon thermal removal of a solvent molecule (usually, $\mathrm{H}_{2} \mathrm{O}$ ) initially bound to the metallic centers (in inorganic nodes of the framework). In this context, the HKUST-1 framework is a typical example.

As it was mentioned above, the most representative examples of MOF-based catalysts for biomass transformation are the MIL-101(Cr) and UiO-66(Zr) (as well as UiO-67(Zr)) frameworks and their derivatives. The reasons for this are their Lewis acidity, open metal sites $\left(\mathrm{Cr}^{3+}, \mathrm{Zr}^{2+}\right)$ and thermal stability of these metal-organic matrices. For instance, zirconium terephthalate $\mathrm{UiO}-66(\mathrm{Zr})$ is a highly active, stable and reusable heterogeneous system for acid catalysis [59]. Moreover, when defects are present in the structure of $\mathrm{UiO}-66(\mathrm{Zr})$, coordinatively unsaturated $\mathrm{Zr}$ ions with Lewis acid properties appear, which assists to the catalytic activity of the resulting defective framework. Therefore, the catalytic activity increases along with the number of missing linkers [13]. However, UiO-66(Zr) type frameworks with an ideal crystalline structure without coordination vacancies also display catalytic activity as Lewis acid solid in some organic transformations like Fisher fatty acid esterification related to biomass upgrading [60]. More detailed characteristics of the UiO-66( $\mathrm{Zr})$ matrix as a catalyst relevant to biomass valorization will be given below.

One more type of metal-organic frameworks is very prospective for biomass valorization. This is a series of zeolite imidazolate frameworks (ZIFs), representing a subfamily of MOF materials that display exceptional chemical and thermal stability, as high as $550^{\circ} \mathrm{C}$. ZIF frameworks are composed of divalent metal nodes linked by imidazolate bridging ligands [61]. Their $145^{\circ}$ metal-imidazolate-metal angles in ZIF structures (Figure 4) are very close to the zeolite Si-O-Si angle, this zeolite-like topology provides the unique stability and robustness of the framework [62]. Due to their unique stability [63] and N-heterocyclic moiety providing specific catalytic performance and hydrophobic properties [64], ZIF matrices are very attractive as heterogeneous catalysts for biomass valorization. 


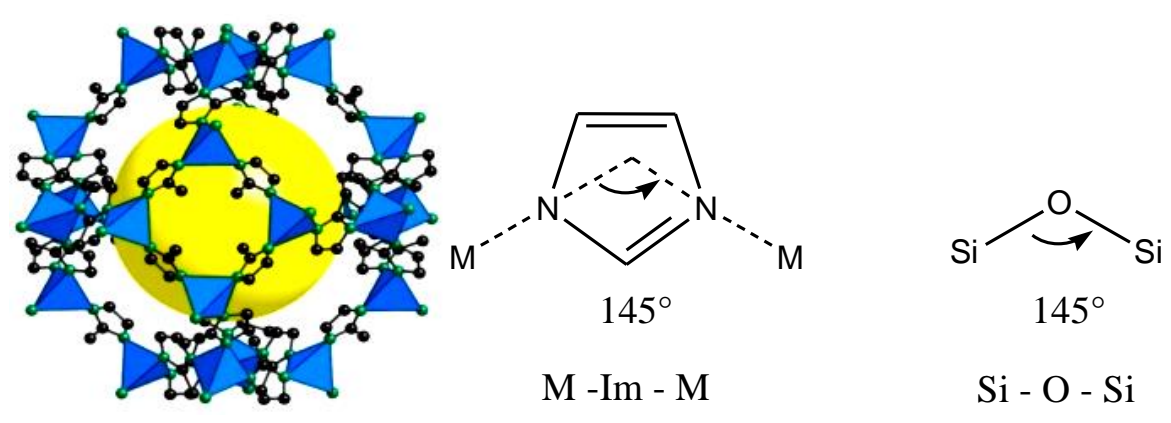

Figure 4. The structure of the ZIF-8 zeolite imidazolate framework. The M-Im-M (2-methylimidazolatemetal angle in ZIF structures is similar to the angle between $\mathrm{Si}-\mathrm{O}-\mathrm{Si}$ bonds in zeolites $\left(145^{\circ}\right)$. Reprinted with permission from reference [61]. Copyright 2010 American Chemical Society.

Another important issue, which can be taken into account is the hydrothermal stability of MOF based catalysts. Essentially, biomass valorization reactions, like dehydration or esterification processes involve an aqueous reaction medium or water generated along with products. Therefore, hydrothermally stable MOF materials, such as MIL-53(Al), MIL-101(Cr), UIO-66(Zr), UIO-67(Zr) and ZIF structures are highly demanded for discussed catalytic processes.

These MOF and ZIF materials can be used as catalysts in a pristine form, as well as post-synthesis and in situ modified for tuning their acid strength regarding the biomass valorization process. For instance, the BDC linker in the UiO-66 and MIL-101(Cr) frameworks can be functionalized by partially or integrally replacing it with analogous organic linkers via direct or post-synthesis modification due to the robustness of the framework [65]. The porous systems in the HKUST-1, UiO-66 and MIL-101(Cr) (2.9 and $34 \mathrm{~nm})$ structures contribute to the encapsulation of the catalytic species, for example, polyoxometallates, metal nanoparticles or poly(N-bromomaleimide) in these host matrices [13]. Particularly, the confinement effect of these frameworks prevents the embedded metal nanoparticles from agglomeration.

In particular, to enhance the functional properties of ZIF materials, a number of efficient methods were developed. There are (1) linker functionalization by post-synthesis modification (PSM) or solvent-assisted ligand exchange (SALE) (or post-synthetic exchange (PSE)); (2) encapsulation of metal and metal oxide nanoparticles (NPs) inside ZIF porous matrices and (3) adsorption or encapsulation of biomolecules [66].

All these strategies regarding the design of the MOF based catalytic materials for biomass valorization will be discussed in the next sections.

\subsection{Choice of MOF Building Blocks}

Since most biomass transformation processes including carbohydrates depolymerization, involve often reactions demanding acidic sites, one of the conditions of MOF-catalyst efficiency is the presence of Lewis and/or Brønsted functionality at metallic centers (inorganic nodes) in the framework. Therefore, a careful selection of MOF building blocks for catalytic biomass valorization is of paramount importance.

The study of four isostructural MOF-74 catalytic materials differed in metallic centers (Co, $\mathrm{Ni}, \mathrm{Mg}, \mathrm{Zn}$ ) shows clearly a strong impact of the metal ions in the sugar conversion into methyl lactate (Figure 5) [67]. The yields of methyl lactate were $16 \%, 19 \%$ and $20 \%$ while using MOF-74(Ni), MOF-74(Zn) and MOF-74(Co), respectively. The MOF-74(Mg) material exhibited the best catalytic activity and a methyl lactate (as the main product) yield of $47 \%$ was obtained from sucrose, while the highest product yield from glucose of $35 \%$ was achieved at optimal reaction conditions $\left(220{ }^{\circ} \mathrm{C}, 6 \mathrm{~h}\right)$. MOF-74(Mg) was also most active for the retro-aldol reaction of fructose to methyl lactate as a main product with a yield of $37 \%$. Simultaneously, the conversion rate of glucose was higher and a slightly higher yield of side products like methyl glycolate and glycol aldehyde dimethylacetal was obtained 
from glucose. As for disaccharides, except sucrose, lower yields of methyl lactate ( $19 \%$ for both lactose and maltose) were achieved. This may be explained by the resistance of these disaccharides to methanolysis under reaction conditions [68].
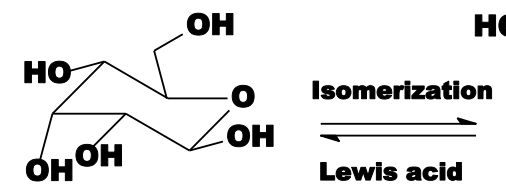

retro

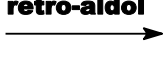

OH<smiles>COC(O)C(C)=O</smiles>

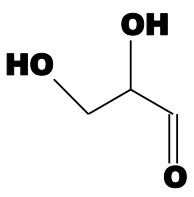

1

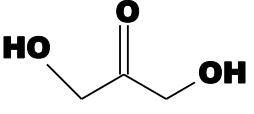

Figure 5. The conversion of glucose into methyl lactate in near-critical methanol solution over MOF-74 catalytic materials.

The reason for the enhanced catalytic performance of MOF-74(Mg) is the presence of stronger Lewis acid sites in this structure [69], which are more efficient for the conversion of glucose [70]. A smaller crystal size and a larger surface area of the MOF-74(Mg) catalyst contribute probably also to its activity. These factors may favor the accessibility of reactants to the active sites. This Mg-based catalyst can be reusable for at least three cycles without deactivation.

The same transformation was studied using other types of MOF materials as catalysts. The ZIF-8 and ZIF-67 zeolitic imidazolate frameworks were tested as catalysts in the conversion of sugars (sucrose, glucose and fructose) into methyl lactate [71]. These matrices have the same sodalite type structure and similar textural properties, namely cavities with sizes of $11.6 \AA$ accessible by small windows of $3.4 \AA$ for the ZIF-8 framework and cavities of $11.4 \AA$ and small windows of $3.3 \AA$ for the ZIF-67 framework [63]. Due to the framework flexibility, the cavities of the ZIF-8 and ZIF-67 catalysts are large enough to accommodate the molecular diameters of glucose and fructose ( $\sim .5 \AA)$ [72].

However, these ZIF catalytic materials display a different catalytic behavior in the sugar conversion into methyl lactate. The reason for this difference is the presence of different metallic centers $\left(\mathrm{Zn}^{2+}\right.$ in ZIF-8 and $\mathrm{Co}^{2+}$ in ZIF-67) in these ZIF frameworks. The ZIF-8 catalytic material is the most active (methyl lactate yield of $42 \%, 160{ }^{\circ} \mathrm{C}, 24 \mathrm{~h}$ ) and can be reused in four catalytic cycles. On the contrary, while using ZIF-67 as a catalyst, the final product yield was only $19.1 \%$. Two factors contributing to this different catalytic behavior were suggested: the crystal size and the Lewis acidity of the metal sites. The crystal size of ZIF-67 is larger (about $1 \mu \mathrm{m}$ ) than that of ZIF-8 (100-150 nm). Therefore, the smaller crystal size improves the accessibility of reactants to the active sites. Another reason is related to the difference in the acid strengths of both catalysts: the ZIF-8 matrix has stronger acid sites, while the acidity of the ZIF-67 material is moderate.

The systematic study of the impact of the metallic centers was carried out with isostructural metal-organic frameworks belonging to the MIL family based on $\mathrm{M}^{3+}$ ions $\left(\mathrm{Al}^{3+}, \mathrm{Fe}^{3+}, \mathrm{Cr}^{3+}, \mathrm{V}^{3+}\right)[73]$. MIL materials have a great potential from the practical point of view due to their high thermal and chemical stability (see previous section). The synthesis of solketal from acetone and glycerol (I) was investigated over catalytic MOF materials, namely, MIL-100(M) and MIL-53(M) (M = V, Al, Fe and $\mathrm{Cr}$ ), as well as mixed MIL-53(Al,V) (Al/V-100/0, 75/25, 50/50, 25/75 and 0/100 atom/atom). The main products were a five-membered solketal (2,2-dimethyl-1,3-dioxane-4-methanol, (II)) and a six-membered acetal (2,2-dimethyl-dioxane-5-ol, (III)) (Figure 6). It was demonstrated that the 
reaction rate and isomer selectivity depend on different parameters such as the type of the metal ion, the length of the $\mathrm{M}-\mathrm{O}$ bond, the rate constant for the exchange of the water molecules from the first coordination sphere of the metal ion and the value of the zero point of the surface charge $\left(\mathrm{pH}_{\mathrm{PZC}}\right)$. In particular, the glycerol conversion decreases in the following order: $\mathrm{V}^{3+}>\mathrm{Al}^{3+}>\mathrm{Fe}^{3+}>\mathrm{Cr}^{3+}$. This order correlates with the value of $\mathrm{pH}_{\mathrm{PZC}}$. The reaction rate and selectivity towards II increase with increasing the $\mathrm{V}^{3+}$ content in the mixed MIL-53( $\left.\mathrm{Al}, \mathrm{V}\right)$ framework. V-containing MOFs possess a high activity and selectivity at $25{ }^{\circ} \mathrm{C}$. The MIL-100(V) and MIL-47(V) metal-organic materials featured the higher efficiencies as compared to strong acids, such as $\mathrm{H}_{2} \mathrm{SO}_{4}, \mathrm{SnCl}_{2}$ and p-toluenesulfonic acid $\left(25^{\circ} \mathrm{C}\right)$. The MIL-100(V) catalyst is reusable for 4 cycles.

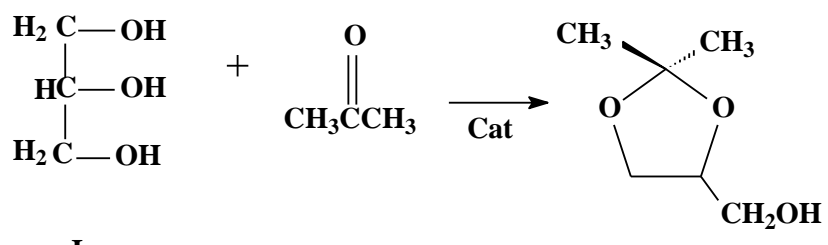

I

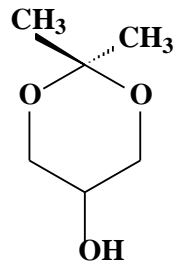

III

Figure 6. Glycerol acetalization over MIL-100(M) and MIL-53(M) catalysts.

Another reason for the differences in the catalytic activity is related to the exchange of water molecules in the first coordination sphere of the metal ion. The isomer selectivity possibly depends on the length of the M-O bond in the MIL framework. The decrease in the length of the M-O bond contributes to the increased II yield. Thus, both high activity and enhanced selectivity towards II are achieved over the V-containing frameworks, MIL-100(V) and MIL-47(V).

$\mathrm{Zr}$-containing hybrid materials have been proven as efficient catalysts for biomass conversion, due to rather strong Lewis acidity [74]. An example of the design of the catalytic MOF materials using $\mathrm{Zr}^{2+}$ ions as inorganic building blocks with strong Lewis acidity are $\mathrm{Zr}$-based metal-organic frameworks with terephthalate $(\mathrm{UiO}-66(\mathrm{Zr}))$ or 2-aminoterephthalate ligands $\left(\mathrm{NH}_{2}-\mathrm{UiO}-66(\mathrm{Zr})\right)$, which are preferential structures for biomass valorization catalysis (see above). Both matrices show activity in the esterification of levulinic acid with $\mathrm{EtOH}, \mathrm{n}-\mathrm{BuOH}$ and long-chain fatty alcohols (Figure 7). This process leads to biomass-derived alkyl levulinates of industrial importance [75]. The catalytic efficiency of the $\mathrm{UiO}-66(\mathrm{Zr})$ and $\mathrm{NH}_{2}-\mathrm{UiO}-66(\mathrm{Zr})$ materials is comparable (and in some cases superior) to the heterogeneous acid catalysts previously reported in the literature, such as supported heteropolyacids and zeolites. In this respect, they are somewhat inferior to highly acidic sulfated mixed $\mathrm{Zr}$ and Ti oxides [76]. The reason for such a superior activity is a synergy of acidity of the metal centers and organic linker functionality in the $\mathrm{NH}_{2}-\mathrm{UiO}-66(\mathrm{Zr})$ catalyst. This synergy is realized as a dual acid-base activation mechanism. In this case, levulinic acid is activated on $\mathrm{Zr}^{2+}$ sites, while alcohol is activated at the amino groups of the linkers, which are Brønsted basic sites.<smiles>CC(=O)CCC(=O)O</smiles><smiles>CCOC(=O)CCC(C)=O</smiles>

Figure 7. Esterification of levulinic acid with $\mathrm{EtOH}$ over $\mathrm{UiO}-66(\mathrm{Zr})$ and $\mathrm{NH}_{2}-\mathrm{UiO}-66(\mathrm{Zr})$ catalytic materials.

Another activity source in the discussed $\mathrm{UiO}-66(\mathrm{Zr})$ and $\mathrm{NH}_{2}-\mathrm{UiO}-66$ catalysts are open metal centers as $\mathrm{Zr}^{4+}$ ions. They represent defect sites formed due to linker deficiency in the framework (see above) and their concentration is dependent critically on the synthesis conditions $[13,36,75]$. 
The particle size impacts also on the catalytic activity of the UiO-66(Zr) material (see below the relevant section).

In addition to organic linkers, metal clusters composed MOF frameworks may be another source of intrinsic Brønsted acidity (and Lewis acidity as well). Z. Hu reported [77] the preparation of two highly stable sulfonated and hierarchically porous MOF structures containing $\mathrm{Zr}$ and $\mathrm{Hf}$ clusters, namely, NUS-6(Zr) $\left(\left[\mathrm{Zr}_{6} \mathrm{O}_{4}(\mathrm{OH})_{8} \mathrm{~L}\right]_{3.5} \cdot \mathrm{xH}_{2} \mathrm{O}, \mathrm{L}=\mathrm{SO}_{3}-\mathrm{BDC}\right)$ and NUS-6(Hf) $\left\{\left[\mathrm{Hf}_{6} \mathrm{O}_{4}(\mathrm{OH})_{8} \mathrm{~L}\right]_{3.5} \cdot \mathrm{xH}_{2} \mathrm{O}\right)$, respectively, by a modulated hydrothermal approach. Both frameworks can be regarded as UiO-66 framework derivatives and topologically are similar to it. On the contrary, the NUS-6(Zr) and NUS-6(Hf) frameworks feature partially missing linkers and $\mathrm{Hf}_{6}\left(\mathrm{Zr}_{6}\right)$ clusters. The hierarchically porous structure of NUS-6(Zr) and NUS-6(Hf) is composed of squashed mesopores $(\sim 2.6 \mathrm{~nm} \times 3.6 \mathrm{~nm}$, measured from $\mathrm{Hf}$ to $\mathrm{Hf}$ vertexes) that are interconnected with microporous tetrahedral and octahedral cavities as in the UiO-66 framework. Such a hierarchically porous structure contributes to the catalyst performance thanks to the dense catalytic sites in micropores and easy mass transfer through mesopores [78].

In the NUS-6(Hf) framework, the $\mu_{3}-\mathrm{OH}$ groups in Hf clusters (which are the inorganic building blocks) could act as Brønsted acid sites. It was shown by acid-base titration that the Brønsted acidity of the NUS-6(Hf) framework is stronger than that of NUS-6(Zr). These MOF materials were used as solid acid catalysts for dehydration of fructose to 5-hydroxymethylfurfural (HMF) (Figure 8). Due to a synergy of strong Brønsted acidity of the Hf-based nodes and sulfonated linkers, the NUS-6(Hf) material exhibited better reaction kinetics and chemoselectivity than that of their Zr-based counterparts (NUS-6(Zr)) in the dehydration of fructose. By using the NUS-6(Hf) catalyst, the quantitative fructose conversion and a HMF yield of $98 \%$ were achieved, which makes this framework one of the best heterogeneous catalysts for such conversion. The superior catalytic activity of NUS-6(Hf) was attributed to its stronger Brønsted acidity as well as more suitable pore size that can inhibit side reactions. Therefore, sulfonated Hf-containing MOF frameworks containing both organic and inorganic Brønsted acid sites should be excellent solid acid catalysts.

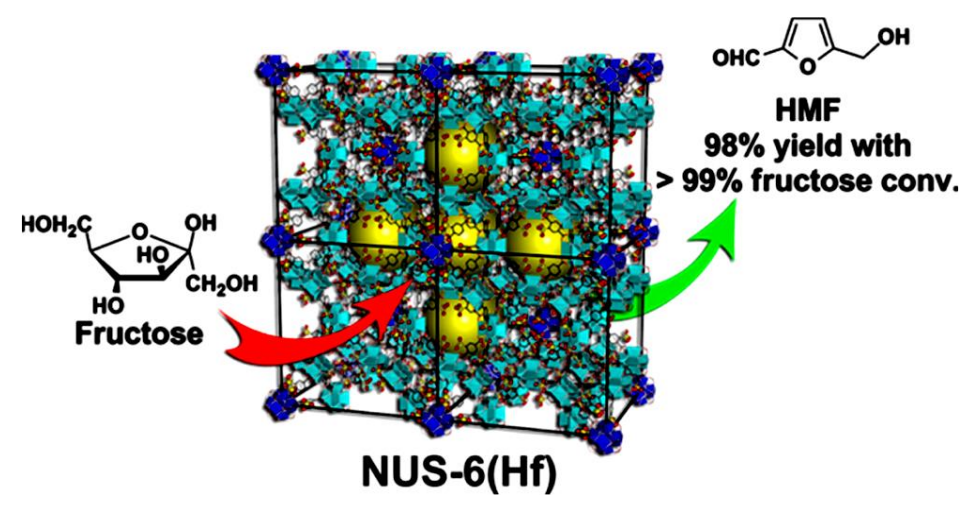

Figure 8. Synthesis of HMF from fructose over hierarchically porous NUS-6(Hf) catalyst. Reprinted with permission from reference [77]. Copyright 2016 American Chemical Society.

Another biomass valorization process governed very much by Lewis acidity is the selective synthesis of monoglycerides by the esterification of glycerol with fatty acids. This is a difficult reaction because of immiscibility of reagents and the formation of di- and tri-glycerides as by-products [79]. A rather distinct amorphous tin-based organic framework with a pore size of ca. $1 \mathrm{~nm}$ demonstrates superiority as the catalyst in the reaction of oleic acid with glycerol compared to zeolites, which were rather inactive in this process. On the contrary, a tin-organic framework (Sn-EOF) with Lewis acidity showed an excellent performance in esterification of oleic acid with glycerol $\left(150{ }^{\circ} \mathrm{C}\right)$. Sn-EOF is an elemental-organic framework (EOF) material constructed from $\mathrm{Sn}^{4+}$ ions connected to the 4,4'-dibromobiphenyl organic linker via element-carbon bonds. 
Sn-EOF displayed a higher activity as compared to other studied MOF-based catalysts with both Lewis and Brønsted acid sites, including their composites with highly acidic heteropolyacids (Keggin anions), such as HPW/HKUST-1, HSiW/HKUST-1, $\mathrm{NH}_{2}$-MIL-53(Al), $\mathrm{NH}_{2}$-MIL-68(In), UiO-66, $\mathrm{NH}_{2}$-UiO-66 and $\mathrm{ZnF}\left(\mathrm{NH}_{2}\right.$-TAZ) materials. Using the Sn-EOF catalyst resulted in achieving an excellent selectivity ( $\geq 98 \%$ monoglyceride) at a $40 \%$ conversion. Ii is important that the Sn-beta zeolite was inactive with an oleic acid conversion of $4 \%(20 \mathrm{~h})$, even below the conversion observed in absence of the catalyst $(20 \%)$.

Leaching of tin from the Sn-EOF catalyst was suppressed by limiting the amount of oleic acid in the starting mixture, because normally oleic acid may cause decomposition of metal-organic frameworks by coordination with metallic centers. This study demonstrates the potential of the unique MOF feature-fine tuning of the catalytic activity by judicious choice of inorganic building blocks in the metal-organic framework for the synthesis of monoglycerides.

As it can be seen from the observed literature examples, the MOF catalysts are mostly bifunctional due to the presence of both Brønsted and Lewis sites in inorganic nodes. However, in most publications relevant to catalytic biomass valorization, the hybrid (or dual) nature of metal-organic framework is involved. Therefore, the catalytic active sites in inorganic nodes of the framework (as a rule with Lewis acidity) are supplemented very often by Brønsted centers in organic linkers. An impact of the organic moiety on the MOF catalyst performance will be discussed below.

\subsection{Organic Linker Choice for MOF Catalyst in Biomass Valorization}

One more efficient strategy for designing MOF catalytic materials for biomass valorization is based on tailoring the functional groups in organic linkers. In these processes, acid functionality is of prime interest. An appropriate organic linker choice allows tuning the catalytic activity by supplementing the Lewis and Brønsted acidity at inorganic ions by Brønsted acidic functionality at organic linkers. Compared to the relatively comprehensive work that has been conducted on the Lewis acidity of MOFs, exploring Brønsted acidity of MOF materials is more challenging and remains less explored [77], mainly because of the weakened framework stability caused by the introduction of Brønsted acidity typically through sulfonic acid groups. There are only very few successful examples of such strategy usage for heterogeneous catalyst design for biomass valorization. One of them is the preparation of the mesoporous $\mathrm{SO}_{3} \mathrm{H}-\mathrm{MIL}-101(\mathrm{Cr})$ framework containing both Lewis acid (as $\mathrm{Cr}^{3+}$ ions) and Brönsted acid sites starting from sulfonated organic building blocks (monosodium 2-sulfoterephthalic acid $\left(\mathrm{BDC}-\mathrm{SO}_{3} \mathrm{Na}\right)$ ) $[80,81]$. The sulfonic groups are accessible-Brønsted acid sites distributed with a high density on the $\mathrm{SO}_{3} \mathrm{H}-\mathrm{MIL}-101(\mathrm{Cr})$ pore surface. The $\mathrm{SO}_{3} \mathrm{H}-\mathrm{MIL}-101(\mathrm{Cr})$ matrix has a high surface area and well dispersed nanocrystals. Thanks to these strong Brønsted acid sites, $\mathrm{SO}_{3} \mathrm{H}-\mathrm{MIL}-101(\mathrm{Cr})$ catalytic material shows a high activity in cellulose hydrolysis into mono- and disaccharides, such as glucose, xylose and cellobiose and demonstrates high durability in the catalytic reaction (Figure 9).

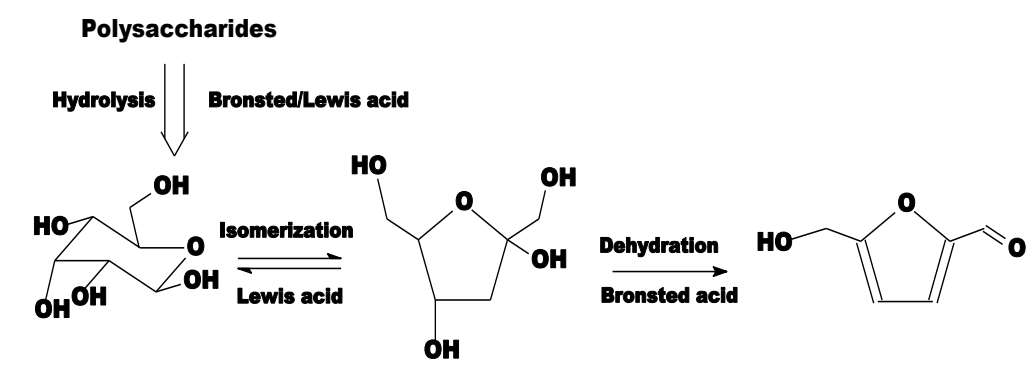

Figure 9. Hydrolysis of polysaccharides and cascade reactions of glucose as a platform chemical to $\mathrm{HMF}$ transformation over $\mathrm{SO}_{3} \mathrm{H}-\mathrm{MIL}-101(\mathrm{Cr})$ material.

The bifunctional $\mathrm{SO}_{3} \mathrm{H}-\mathrm{MIL}-101(\mathrm{Cr})$ material mentioned above was extensively studied in challenging and practically demanding processes-cascade reactions of glucose as a platform chemical 
to HMF transformation [80,82]. This process involves isomerization over Lewis acid sites followed by the dehydration to HMF over Brönsted acid sites (Figure 9). It could be complicated by the formation of undesirable side products through an extra-isomerization step leading to a decrease of the HMF yield. A number of solid acid catalysts were examined in this process and relevant experimental results showed that these heterogeneous systems afforded lower HMF yields than those obtained using homogeneous catalysts. Some MOF materials were also studied in the glucose into HMF conversion. However, using them gave only low yields of the target products-below $16 \%$. The modification of organic benzene-1,4-dicarboxylate linkers of the MIL-101(Cr) material with sulfonic acids has been proven as a promising strategy for an enhancement of its catalytic activity. The bifunctional MIL-101- $\mathrm{SO}_{3} \mathrm{H}$ catalyst can promote an isomerization of glucose to fructose, while the $-\mathrm{SO}_{3} \mathrm{H}$ groups are active Brönsted acid sites for the fructose dehydration (Figure 10).

This strategy resulted in achieving a $29 \%$ conversion of glucose $\left(24 \mathrm{~h}, \mathrm{THF}: \mathrm{H}_{2} \mathrm{O}(v: v=39: 1)\right.$ mixture) over a functionalized $\mathrm{SO}_{3} \mathrm{H}-\mathrm{MIL}-101(\mathrm{Cr})$ ) catalyst. This conversion level is lower as compared to traditional acid catalysts, such as mesoporous tantalum phosphate and Sn montmorillonite $[13,80]$. As a rematch, this MOF catalyst features a high selectivity of $80 \%$ to HMF over levulinic acid. This selectivity level is much higher than that achieved using other inorganic systems, such as Amberlyst-15 and sulfuric acid, which gave mostly levulinic acid. It was found that the $\mathrm{SO}_{3} \mathrm{H}-\mathrm{MIL}-101(\mathrm{Cr})$ ) material is inactive in the isomerization of glucose to fructose.

The $\mathrm{SO}_{3} \mathrm{H}-\mathrm{MIL}-101(\mathrm{Cr})$ matrix retains its porous and crystalline structure during catalytic cycles. However, this catalyst has a sufficient drawback, such as pore blocking in the catalysis course by the formation of bulky humins. Therefore, a reactivation step is needed during exploitation of the $\mathrm{SO}_{3} \mathrm{H}-\mathrm{MIL}-101(\mathrm{Cr})$ material.

The same sulfonic acid functionalized MIL-101(Cr)-SO ${ }_{3} \mathrm{H}$ material was examined as the catalyst for HMF synthesis in an integrating process involving biomass-derived $\gamma$-valerolactone-mediated dehydration of glucose [80]. Under the optimal reaction conditions $\left(150^{\circ} \mathrm{C}, 120 \mathrm{~min}\right)$ in a fixed-bed reactor, an HMF yield was $44.9 \%$ and selectivity of $45.8 \%$. Noteworthy, using this MOF catalyst resulted in a steady HMF yield.

The next example of an enhanced catalytic performance of a sulfonated $\mathrm{SO}_{3} \mathrm{H}-\mathrm{MIL}-101(\mathrm{Cr})$ material is the conversion of furfuryl alcohol (FA) into ethyl levulinate (EL) [83]. A target product yield of $79.2 \%$ at a $100 \%$ FA conversion in ethanol was achieved over this bifunctional MOF catalyst. The $\mathrm{SO}_{3} \mathrm{H}-\mathrm{MIL}-101(\mathrm{Cr})$ material shows a superior performance to other sulfonic acid-functionalized solid catalysts in this transformation (Figure 10). In particular, a density and strength of $-\mathrm{SO}_{3} \mathrm{H}$ Brønsted acid sites placed in the organic linker sites is a key factor impacted on this catalyst performance. Actually, the $\mathrm{SO}_{3} \mathrm{H}-\mathrm{MIL}-101(\mathrm{Cr})$ material displayed a higher catalytic activity as compared to the performance of other sulfonated MOF matrices, such as the $\mathrm{SO}_{3} \mathrm{H}-\mathrm{UiO}-66(\mathrm{Zr})$ framework $(23.4 \% \mathrm{FA}$ conversion, 3.1\% EL yield, 20.8\% 2-ethoxymethylfuran yield), which is characterized by a lower density of Brønsted acid sites.

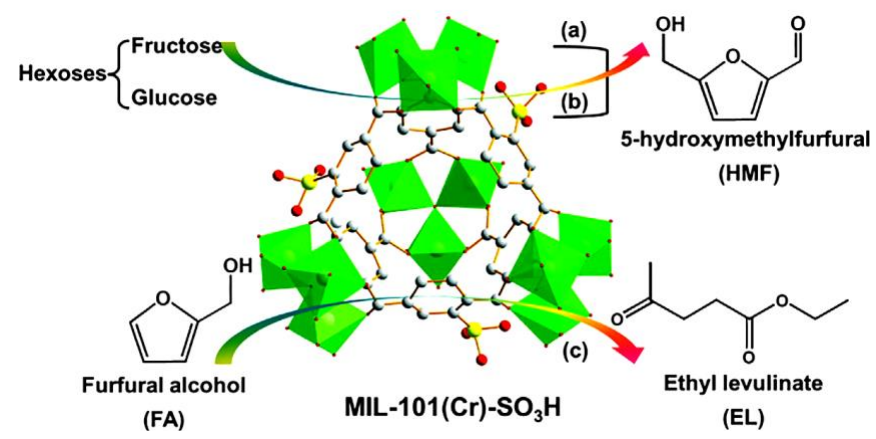

Figure 10. Transformations of (a) fructose and (b) glucose into HMF and (c) furfural alcohol into ethyl levulinate over $\mathrm{SO}_{3} \mathrm{H}-\mathrm{MIL}-101(\mathrm{Cr})$. Reprinted with permission from reference [36]. Copyright 2016 Viley-VCH. 
It can be seen from the observed literature, that the choice of the functionalized organic linkers as well as archetypical metal-organic frameworks in whole for engineering an acid MOF catalyst is rather limited. Other approaches, that is, the post-synthesis modification and in-situ synthesis of the functionalized MOF matrices, allow one to expand a range of possible catalytic MOF materials for biomass processing.

\subsection{Post-Synthesis Modification of MOF Structures}

As it was mentioned above, one of the most distinct MOFs characteristics is a possibility of their rational design by post-synthetic modification of their organic or inorganic building blocks with appropriate functional groups or introducing the functional species inside pore voids via template synthesis in-situ. To date, numerous works reported the efficiency of the preparation of MOFs-based catalytic systems using these ways [84-86].

Here we present some important results concerning tuning the MOF catalyst activity in biomass upgrading by post-synthesis modification through grafting organic molecules containing appropriate functional groups to coordinatively unsaturated sites and introducing organic molecules with a desirable function in organic linkers. Encapsulation of functional species and molecules in MOF host matrices will be discussed in the "MOF-based composite" section. We consider below the illustration of these approaches taking catalytic depolymerization of carbohydrates as a most representative example.

As it was mentioned above, despite of their rather strong Lewis acidity, most MOF materials are lacking Brønsted acidity for efficient catalytic processes of biomass valorization, first of all, for sugar dehydration reactions. Besides the one-pot synthesis using organic building blocks with appropriate functionalities, the most common method of introducing Brønsted acidity to MOFs catalysts is by post-synthetic modifications. In most cases, sulfonic acid groups are introduced using this strategy. However, such supplementary acidification of MOF materials can result in some stability and crystallinity loss. Therefore, only robust structures can be modified by this post-synthetic approach for introducing functional organic sites [87] that could be used directly or after post-synthesis modifications. An example is a post-synthetically modified UiO-66( $\mathrm{Zr}$ ) framework in which Brønsted acid sites are introduced [88]. A benefit of such post-synthesis modification is the creation of the bifunctionality in the framework, that is, generation of both Lewis and Brönsted acid sites. Such dualism of active sites is achieved with simultaneous appropriate selection of inorganic nodes $\left(\mathrm{Zr}^{4+}\right)$ with Lewis acidity and post-synthesis modification of organic linkers by sulfo functionalities.

\subsection{Post-Synthesis Modification of Inorganic Nodes}

The grafting of ligands with additional functional moieties to inorganic nodes is not trivial, since such groups may directly coordinate to the metal ions [50]. An elegant way of tuning the selectivity of active acid sites by post-synthesis modification of inorganic nodes in the NU-1000 metal-organic framework was demonstrated in [89]. The NU-1000 structure is composed of the $\mathrm{Zr}_{6}\left(\mu_{3}-\mathrm{OH}\right)_{4}\left(\mu_{3}-\mathrm{O}\right)_{4}(\mathrm{OH})_{4}\left(\mathrm{OH}_{2}\right)_{4}$ nodes $\left(\mathrm{Zr}_{6}\right.$ nodes) and tetratopic 1,3,6,8-tetrakis ( $p$-benzoate)pyrene (TBAPy) linkers. While the UiO-66 and UiO-67 structures discussed above feature 12-connected $\mathrm{Zr6}$ nodes, NU-1000 is composed of 8-connected Zr6 nodes and contains terminal water and hydroxyl ligands in addition to $\mu 3$-bridging hydroxyl and oxido groups [90]. The NU-1000 framework has wide mesoporous channels with a diameter of $31 \AA$ and smaller pores connected perpendicularly to these large pores that allow the diffusion of a substrate throughout the material. This hierarchical nanoporous structure contributes to exploring this matrix as a catalyst or a catalyst support [91,92].

The NU-1000 metal-organic framework was studied in glucose transformation to HMF. Noteworthy, its strong Lewis acid sites in $\mathrm{Zr}_{6}$ nodes are too reactive and catalyze undesired side reactions. To enhance the selectivity of this MOF catalyst, a partial phosphate modification of zirconia-cluster nodes in the NU-1000 framework was carried out in order to poison unselective active sites with phosphoric acid by forming the oxo substituents of grafted phosphate species. The NU-1000 
catalyst modified by this method demonstrates both a high yield of HMF and selectivity ( $64 \%)$, at an initial glucose concentration of $1 \mathrm{mM}$ in water/2-propanol. In contrast, complete replacement of Lewis sites with Brønsted acid sites using the same strategy reduces the catalytic performance of the NU-1000 material. The authors conclude that the ideal catalyst for the studied process should be bifunctional one. In other words, both moderate Lewis acidity as well as Brønsted acid sites in the NU-1000 matrix are demanded. On the contrary, similar partial phosphate modification of bulk zirconia results in a considerable reduction of the HMF selectivity. Ii is important to note that this selectivity drop is observed despite the fact that this inorganic material has almost identical Brønsted acidity to the selective NU-1000 system.

An important issue or critical point for practical exploitation of MOF catalysts is their insufficient hydrothermal stability and poor resistance to acidic medium, which hinder their usage as catalysts in dehydration reactions to produce biofuels or fine chemicals. As it was mentioned above, the mesoporous MIL-101(Cr) framework is a bifunctional material featuring the dual character of $\mathrm{Cr}^{3+}$ ions in inorganic nodes as open sites assisting to substrate coordination and simultaneously serving as Lewis acidic sites catalyzing cascade reactions relevant to the biomass transformation. Thanks to this bifunctionality, the MIL-101(Cr) material displays an enhanced catalytic performance in xylose dehydration yielding $49 \%$ of target furfural $\left(170^{\circ} \mathrm{C}\right)$. However, this material can be utilized only in 4 catalytic cycles. Post-synthesis modification of coordinatively-unsaturated $\mathrm{Cr}^{3+}$ centers in the MIL-101(Cr) framework with hydrophobic octadecyltrichlorosilane (OTS) allows one to improve the hydrothermal stability of this matrix. The protection of the $\mathrm{Cr}^{3+}$ active sites by silane groups contributes to the retention of the crystalline structure of the OTS-MIL-101(Cr) framework with a different extent of OTS modification as compared to the pristine MIL-101(Cr) material under severe conditions of xylose dehydration (an elevated temperature in combination with eliminated water). Therefore, the modified framework 0.5-OTS-MIL-101(Cr) (with OTS content of 50\%) allows one to increase the furfural yield (56\%). Simultaneously, a dramatic improvement of its catalytic durability is another benefit of this functionalization. As a result, the 0.5-OTS-MIL-101(Cr) material can be exploited without any activity loss during up to 8 catalytic cycles [93].

\subsection{Post-Synthesis Modification of Organic Linkers}

A series of sulfonic acid-functionalized metal-organic frameworks $\left(\mathrm{MOF}-\mathrm{SO}_{3} \mathrm{H}\right)$, namely, MIL-101(Cr) [SO $\left.{ }_{3} \mathrm{H}-\mathrm{MIL}-101(\mathrm{Cr})\right], \mathrm{UiO}-66(\mathrm{Zr})$ [SO $\left.{ }_{3} \mathrm{H}-\mathrm{UiO}-66(\mathrm{Zr})\right]$ and MIL-53(Al) [SO$\left.{ }_{3} \mathrm{H}-\mathrm{MIL}-53(\mathrm{Al})\right]$, were prepared by post-synthetic modification of the organic linkers with chlorosulfonic acid [94]. The effect of this functionalization with Brønsted acid sites was studied in fructose transformation to $\mathrm{HMF}$ over MOF-SO${ }_{3} \mathrm{H}$ catalysts. Important to note, this is the main process, in which MOF catalysts with linkers functionalized with Brønsted acid (mostly, sulfo-modified linkers) are extensively studied. The $\mathrm{SO}_{3} \mathrm{H}-\mathrm{MIL}-101(\mathrm{Cr})$ framework was selected as the most representative catalyst among modified MOF-SO ${ }_{3} \mathrm{H}$ matrices. Using this catalyst resulted in a high $\mathrm{HMF}$ yield of $90 \%$ with a complete fructose conversion $\left(120^{\circ} \mathrm{C}, 60 \mathrm{~min}\right.$, dimethylsulfoxide (DMSO)). The concentration (or density) of sulfonic groups in $\mathrm{MOF}-\mathrm{SO}_{3} \mathrm{H}$ materials corresponded to the $-\mathrm{SO}_{3} \mathrm{H}$ grafting degree. At a lower $-\mathrm{SO}_{3} \mathrm{H}$ grafting extent, a good linear correlation between the catalytic activity (turnover frequency) and sulfonic acid site density of $\mathrm{MOF}-\mathrm{SO}_{3} \mathrm{H}$ materials was found. Moreover, sulfonic acid groups as Brønsted acid sites are equivalent as catalytically active centers in all modified $\mathrm{MOF}-\mathrm{SO}_{3} \mathrm{H}$ matrices, regardless of the pristine MOF frameworks. Both the conversion of fructose and selectivity towards HMF increase with the sulfonic acid site density in $\mathrm{MOF}-\mathrm{SO}_{3} \mathrm{H}$ at the initial stage of fructose transformation. It was found that only fructose in sucrose and inulin was converted into HMF. The obtained modified MOF materials, in particular, the $\mathrm{SO}_{3} \mathrm{H}-\mathrm{MIL}-101(\mathrm{Cr})$ catalyst, are reusable and can be utilized several times. Noteworthy, (15\%) SO 3 H-MIL-101(Cr) and NUS-6(Hf) are among the best heterogeneous catalysts reported so far for the conversion of fructose into HMF [13,77].

Glycerol carbonate (GC), derivative of glycerol, is a valuable intermediate for the production of polycarbonates and polyurethanes [95]. To date, it is produced by glycerolysis of urea over inorganic 
salts such as $\mathrm{ZnSO}_{4}, \mathrm{MgSO}_{4}$ and $\mathrm{ZnO}$ and some heterogeneous systems, such as hydrotalcites based on these oxides [96]. It was found that the catalyst bifunctionality, that is, the simultaneous presence of the acid and basic sites, contributed significantly to the catalyst performance in the synthesis of cyclic carbonates from urea and diols. A bifunctional MOF catalyst having an appropriate combination of Lewis acid and Lewis basic sites was developed specifically for this process [97]. This material, that is, the IRMOF-3 framework $\left(\mathrm{Zn}_{4} \mathrm{O}(\mathrm{BDC})_{3}\right)$ with amino functions in organic linkers was modified by a post-synthesis strategy by alkyl halides resulted in the conversion of $-\mathrm{NH}_{2}$ to a quaternary ammonium salt species. Functionalized F-IRMOF-3 materials have quaternary ammonium groups (1.0-4.3 $\mathrm{mg}$ of $\mathrm{N}^{+} / \mathrm{g}$-cat). Therefore, these systems possess electrophilic sites $\left(\mathrm{Zn}_{4} \mathrm{O}\right.$, inorganic building blocks) and nucleophilic centers $\left(\mathrm{X}^{-}\right)$. Thanks to this bifunctionality, F-IRMOF-3 materials display an enhanced activity in the solvent-free glycerolysis of urea into glycerol carbonate as compared to other heterogeneous systems. The F-IRMOF-3 catalyst with a larger alkyl chain in the organic linker and a more nucleophilic counter anion is more active in the synthesis of GC. The conversion of glycerol over the F-IRMOF-3 material with $\mathrm{I}^{-}$species was higher as compared to analogous modified catalysts with $\mathrm{Cl}^{-}$and $\mathrm{Br}^{-}$counter anions. This effect could be attributed to the nucleophilicity of the counter anion, so the $\mathrm{I}^{-}$counter ion is much more nucleophilic as compared to other studied halide anions.

The preparation procedure impacts significantly on the catalytic properties of the F-IRMOF-3 matrices, because defects in the framework, such as $\mathrm{ZnO}$ and $\mathrm{Zn}-\mathrm{OH}$ species are formed mainly during the fast precipitation procedure as compared to the convenient solvothermal method, thanks to the introduction of acid-base bifunctional active sites. The combination of the $\mathrm{ZnO}$ and $\mathrm{Zn}-\mathrm{OH}$ species serving as supplementary acid sites and free amino groups in the linkers that are basic sites enhances also the F-IRMOF-3 catalyst performance.

Thus, the reported results show an efficiency of post-synthesis modification strategy for the design of MOF catalysts exploited in diverse biomass valorization processes.

\section{MOF Based Hybrid Nanomaterials and MOF-Derived Nanostructures in Biomass Valorization}

\subsection{MOF-Based Hybrid Nanomaterials}

The fascinating properties of MOFs pave the way for their numerous applications. The obvious obstacles on this route are the insufficient thermal, mechanical and chemical stability as well as the lack of appropriate catalytic sites. These MOF materials weak points do not allow one to exploit fully their potential in practice. Therefore, there is a need to further enhance and tune the functional properties of MOF materials for a specific process using appropriate procedures. Integration of MOF matrices with a variety of functional materials and species is an efficient strategy to introduce new functionality leading to further improvement of their performance for practical use. To date, a number of comprehensive reports deal with a combination of MOFs with various materials in order to produce new functional hybrids or composites $[66,98]$. These hybrid nanomaterials were prepared by assembling metal-organic frameworks and functional species, organic molecules, metal nanoparticles, metal oxides, polyoxometallates (POMs) and metal complexes as well as other types of matrices including graphene, carbon nanotubes (CNTs), MMS silicas and nanorods $[99,100]$. Some of MOF based hybrid nanomaterials were tested in heterogeneous catalysis including biomass conversion. According to imparted extra properties, the MOFs based hybrids can be divided into two main groups: (1) imparting the additional catalytic properties and (2) acquiring the stability (hydrothermal, mechanical strength and so forth.) [101-103].

Despite the advantages of MOFs for catalysis indicated above, the type of active sites on pristine metal-organic frameworks is mainly limited to the following two sources: unsaturated metal centers and organic ligands, which catalyze a limited pool of reactions (see previous sections). In addition to approaches aimed at introducing active sites in MOF matrices mentioned in the previous sections (a careful evaluation of network building blocks and their post-synthesis modification), MOFs as nanoporous materials are able to accommodate guest species (e.g., metal complexes, enzymes and 
metal NPs (MNPs)) into their pore space by a noncovalent interaction. The guest@MOF prepared in this way can display a synergistic effect in catalytic reactions. The main benefit of this synergy is extending the potential applications of MOF materials in catalysis.

In terms of the catalytic application, MOF hybrids show some superior characteristics because of the unique features of MOFs mentioned above. For example, the high porosity with ordered crystalline pores and high surface areas contribute to the uniform dispersion and the high density of catalytic sites, which can improve the catalytic efficiency [104]. The confined pore sizes can limit active species (such as metal nanoparticles) growth and agglomeration and selectively transport different substrate molecules for size-selective (or shape-selective) catalysis [105]. These superior characteristics provide a potential of these hybrid materials in heterogeneous catalysis, in which MOF hybrids could display an enhanced activity, stability and reusability.

\subsection{Embedding Catalytic Active Sites in MOF Host Matrices by Template Synthesis}

The extra-large cavities and high surface area of MOF matrices make them ideal hosts for embedding large molecules, such as dyes, metalloporphyrins, metal nanoparticles, or nanosized POM clusters $[83,103]$. In view of functionalizing the MOF pores or cavities, catalytically active species or molecules could be encapsulated in the pores by two ways: (1) introducing the functional molecules by a template or in-situ approach ("a ship around the bottle," template synthesis) or (2) encapsulation of nanoparticles by post-synthesis modification ("ship in a bottle") [103,106,107]. Template in-situ synthesis involves the incorporation of functional molecules or particles during the MOF material synthesis. Currently, the potential of this pathway for the preparation of MOF-based hybrids as catalytic materials for biomass upgrading was justified by a number of examples [108,109]. The template in-situ synthesis for preparation of MOFs-based hybrid nanomaterials, first at all, for polyoxometallates (POMs) embedding will be reviewed below.

POMs along with MOFs are another type of highly ordered catalytic materials. They are soluble metal oxygen anion clusters of d-block transition metals in high oxidation states: $\mathrm{W}(\mathrm{VI}), \mathrm{Mo}(\mathrm{V})$, $\mathrm{Mo}(\mathrm{VI}), \mathrm{V}(\mathrm{IV}), \mathrm{V}(\mathrm{V})$ [110]. Two most important features of POMs contributing to catalysis applications are their strong acidity and redox properties, which can be controlled by changing the chemical composition [111]. These materials demonstrate thermal and chemical stability, particularly in multi-electron redox reactions. It is possible to tailor the catalytically active sites of POMs at the molecular or atomic level. All these characteristics make POMs promising oxidation and acid catalysts.

Particularly, heteropolyacids as a most important type of POMs are widely used for the conversion of biomass due to their Brønsted acidity and high proton mobility [112,113]. Unfortunately, POMs have some drawbacks that limit their applications such as small surface areas $\left(<10 \mathrm{~m}^{2} \mathrm{~g}^{-1}\right)$, low stability under catalytic conditions and high solubility in aqueous solutions [111].

The optimal way to exploit the catalytic properties of POMs is to deposit them on a porous support with a high surface area and to combine the activity of POMs with the reusability and recyclability of heterogeneous catalysts [113]. MOF materials are promising matrices for the encapsulation of POMs due to their textural and structural characteristics. Additionally, metal-organic frameworks have often own active sites, so the catalysis synergy between them and POMs reactivity can be obtained [114].

In the previous section, imparting of the Brønsted acidity to the mesoporous MIL-101(Cr) framework by using sulfonated organic linkers was discussed. Embedding POMs clusters is another strategy to create Brønsted acid sites in this matrix. The porous MIL-101(Cr) host is considered as a material of choice for POM encapsulation due to large cavities allowing the diffusion of reactants after introducing these guest species. The hybrid material obtained in this way was studied in the tandem reaction of fructose into 2,5-diformylfuran (DFF) conversion involving the dehydration of fructose to HMF catalyzed by an acid catalyst and subsequent oxidation of HMF to DFF by a redox catalyst [115]. To carry out this transformation, the synergy of bifunctional acid sites in the MIL-101(Cr)-based catalyst was imparted by encapsulation of phosphomolybdic acid (PMA) in this porous host. The PMA@MIL-101(Cr) host-guest material features a strong Lewis acidity $\left(\mathrm{Cr}^{3+}\right.$ 
ions) and Brønsted acidity (PMA clusters), as well as a moderate redox potential. The generated multifunctionality of active sites provides a high activity and selectivity of the PMA@MIL-101(Cr) hybrid in one-pot synthesis of 2,5-diformylfuran (DFF) directly from fructose, yielding $75.1 \%$ of DFF as a target product. This bifunctional catalyst also demonstrated the recyclability in the studied process.

A series of hybrid materials was prepared by encapsulation of another type of POM clusters-phosphotungstic acid, $\mathrm{H}_{3} \mathrm{PW}_{12} \mathrm{O}_{40}$ (PTA), in the MIL-101(Cr) host matrix by one-step in-situ synthesis. PTAx@MIL-101 hybrids modified with Brønsted acid functionalities from PTA (with different PTA weight loading) were exploited in selective dehydration of fructose and glucose [116]. Noteworthy, PTA is needed as a source of the Brønsted acid functionality, because Lewis sites $\left(\mathrm{Cr}^{3+}\right.$ ions) in the MIL-101(Cr) framework are not active in the dehydration of carbohydrates (see previous sections). The catalytic activities of the resulting PTAx@MIL-101 hybrids depended on the PTA loading and the optimal one was $0.3 \mathrm{wt} \%$. By using the PTA (3.0)@MIL-101(Cr) hybrid, an HMF yield of $63 \%$ from fructose was obtained $\left(30 \mathrm{~min}, 130^{\circ} \mathrm{C}, \mathrm{DMSO}\right)$. This catalyst is quite stable and almost no PTA leaching $(\sim 2 \%)$ is observed during the reaction course.

Fine tuning of the catalytic performance of the MIL-101(Cr) framework as a solid acid used for the challenging transformation of glucose to HMF in has been reported [117]. For this purpose, the combined way to simultaneous modification both with sulfonic acid in organic linkers and with PTA in the cavities was studied. A host-guest material PTA@MIL-101(Cr)-SO ${ }_{3} \mathrm{H}$ hybrid was prepared by self-assembly in-situ (or template synthesis) under hydrothermal conditions. It is regarded as the optimal catalyst (as compared to its counterpart MIL-101(Cr)-SO ${ }_{3} \mathrm{H}$ without PTA guest species), which induced the isomerization and cyclodehydration of glucose in one pot. The PTA@MIL-101(Cr)-SO $\mathrm{SO}_{3} \mathrm{H}$ multifunctional catalyst provided over $99.9 \%$ glucose conversion and a HMF yield of $80.7 \%\left(80^{\circ} \mathrm{C}, 4 \mathrm{~h}\right.$, in water). Importantly, the PTA@MIL-101(Cr)-SO ${ }_{3} \mathrm{H}$ catalyst allows the authors to achieve the HMF yield in the cheap glucose conversion, which is comparable to the HMF yield (85.3\%) afforded in the expensive fructose conversion. The catalyst is quite reusable and recyclable without any noticeable activity loss.

Along with the MIL-101(Cr) matrix, the microporous HKUST-1 framework based on $\mathrm{Cu}^{2+}$ ions is among the MOF matrices most studied for POMs embedding [118]. The HKUST-1 material having a large surface area $\left(1500 \mathrm{~m}^{2} / \mathrm{g}\right)$ and suitable cavities can be used as a host matrix for the encapsulation of the POM nanoclusters to form an insoluble and recyclable catalyst for biomass conversion. It should be noted that due to the relatively small size of the HKUST- 1 cavities (7 and 9.6 $⿱$ )), only monomeric Keggin-type POMs can be incorporated. Noteworthy, these guest species exhibit a template effect during the formation of the MOF material [119].

Some of POMs@HKUST-1 hybrids were studied as heterogeneous catalysts in biomass valorization. An example is encapsulation of Keggin-type POMs (namely HPM (HPM = phosphomolybdic acid hydrate) in the HKUST-1 porous host [120]. The resulted HPM@HKUST-1 hybrid or NENU-5 was prepared by a one-step co-precipitation method. According to physico-chemical characterization, the as-synthesized material features the localization of HPM molecules in the largest pores of the Cu-BTC host (9.6 ̊ nm). The homogeneous distribution of HPM in the pores of the HKUST-1 matrix provides the combination of the catalytic activity of HPM and the insolubility, large surface area and hierarchical pore structure of the metal-organic framework. The catalytic performance of the HPM@HKUST-1 hybrid was tested in the etherification of HMF with ethanol, reaching a $55 \%$ yield of EMF (5-ethoxymethylfurfural) and an $11 \%$ yield of EL $\left(100^{\circ} \mathrm{C}, 12 \mathrm{~h}\right)$. This catalyst showed a good reusability after five cycles.

A series of nanosized hybrid materials was synthesized using the HKUST-1 host matrix for encapsulation of different POMs (Keggin ions) including $\mathrm{H}_{3} \mathrm{PW}_{4} \mathrm{O}_{12}, \mathrm{H}_{5} \mathrm{PMo}_{12} \mathrm{O}_{40}, \mathrm{H}_{5} \mathrm{PVMo}_{10} \mathrm{O}_{40}$, $\mathrm{H}_{5} \mathrm{PV}_{2} \mathrm{Mo}_{10} \mathrm{O}_{40}, \mathrm{H}_{5} \mathrm{PV}_{3} \mathrm{Mo}_{10} \mathrm{O}_{40}$ [121]. The structural examinations showed that the Keggin ions acted as template species during the synthesis of the metal-organic framework. POM@HKUST-1 host-quest materials were exploited in selective oxidation of glycerol with $\mathrm{H}_{2} \mathrm{O}_{2}\left(40{ }^{\circ} \mathrm{C}\right.$, water) into valuable esters. POM served as the active sites for this oxidative esterification process demanding weak acidity 
provided by $\mathrm{H}_{2} \mathrm{O}_{2}$ as the oxygen source. The selectivity to esters was $34.5 \%$ in this one-pot oxidative esterification process. Such selectivity is caused by the porous HKUST-1 structure that provides the specific environment for POM active sites. Thanks to the pore limitation effect, diffusion was restricted assisting to ester formation over encapsulated POM (Figure 11). These POM@HKUST-1 catalysts could be recovered after the reaction, thereby exhibiting good stability and reusability without POM leaching.

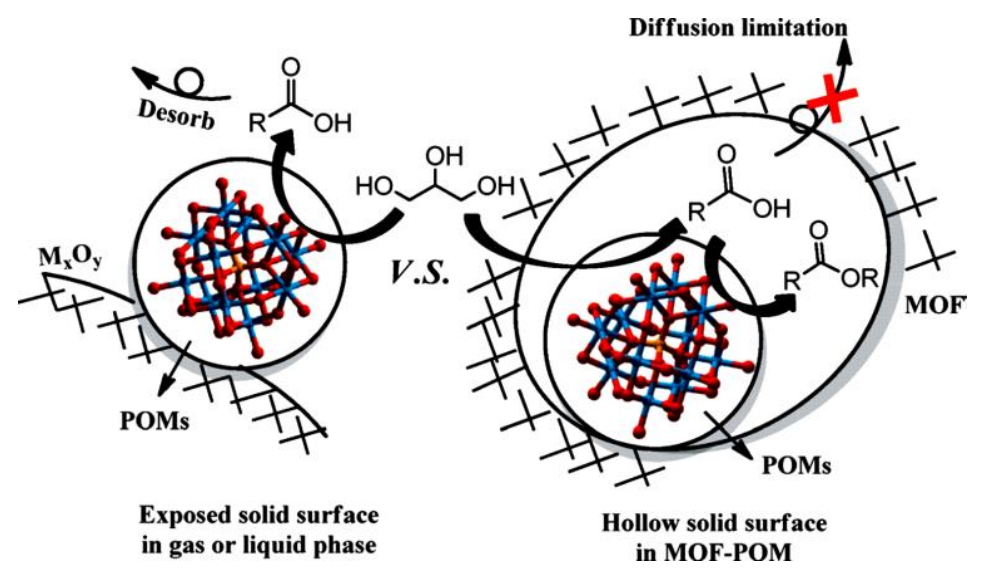

Figure 11. Diffusion limited glycerol transformation over a POMs@HKUST-1 hybrid catalyst. Reprinted with permission from reference [121]. Copyright 2015 Royal Society of Chemistry.

To date, examples of in-situ modification of MOF matrices with guest particles other than POMs are rather scarce. An efficient route for tuning the MIL-101(Cr) catalytic activity by deposition of co-precipitated $\mathrm{Cr}(\mathrm{OH})_{3}$ nanoparticles was demonstrated in [122]. A $\mathrm{Cr}(\mathrm{OH})_{3} / \mathrm{MIL}-101(\mathrm{Cr})$ hybrid with bifunctional Lewis $\left(\mathrm{Cr}^{3+}\right.$ ions) and Brønsted acid sites $\left(\mathrm{Cr}(\mathrm{OH})_{3}\right)$ was prepared via a one-pot synthesis method. The combination of base-like chromium hydroxide particles and Lewis acidic sites of MIL-101(Cr) results in a highly selective conversion of glucose to fructose $\left(100{ }^{\circ} \mathrm{C}, 24 \mathrm{~h}\right.$, ethanol) with a product distribution of $23.5 \%$ glucose, $59.3 \%$ fructose and $2.9 \%$ mannose. The fructose yield obtained over the $\mathrm{Cr}(\mathrm{OH})_{3} / \mathrm{MIL}-101(\mathrm{Cr})$ material is comparable with the performance of optimized Sn-containing zeolites demonstrating strong Lewis acidity, such as Sn-Beta [123].

\subsection{Hybrid Materials in the Form of MOF Host Matrices Containing Embedded Metal Nanoparticles}

To date, there are limited reports on the application of MOFs as catalysts for biomass valorization, which mainly focus on functionalized MOFs as solid acid catalysts for dehydration and hydrolysis of biomass. There are very few examples of application of NPs@MOFs nanocatalysts for these processes [36]. As far as MOFs are successfully employed in catalytic applications, they must be stable and resistant to degradation under the established conditions, which can include changes in chemical and thermal environments in challenging transformations of biomass. As to the supported active phase, the structure of metal-organic frameworks can provide different anchoring sites for the reactants. In this case, the MOF-based heterogeneous system acts as a bifunctional catalyst thanks to both interesting adsorption and catalytic properties [124].

As a rule, most M NPs@MOF hybrids are used in hydrogenation as a key step in many processes of biomass transformations. The relevant investigations show that using these MOF based catalysts allows significant selectivity improvement in these reactions [125]. For instance, the MIL-101(Cr) matrix containing embedded Ru nanoparticles demonstrated a high efficiency in the selective hydrogenation of furfural to cyclopentenone, which is a useful way to the sustainable synthesis of important chemicals from biomass [126]. Particularly, cyclopentanone is a versatile reagent in the synthesis of insecticides, medicines and perfume and can serve as a solvent in the electronics industry [127]. Using a Ru@MIL-101(Cr) nanocatalyst resulted in a complete conversion of furfural with a selectivity higher than $96 \%$ in an aqueous media $\left(2.5 \mathrm{~h}, 160^{\circ} \mathrm{C}, 4.0 \mathrm{MPa} \mathrm{H}_{2}\right.$ pressure). The Ru@MIL-101(Cr) 
catalyst features the homogeneous dispersion of very small Ru NPs (4-5 nm) and density of Lewis acid sites due to specific acidic functionality and structural properties of the MIL-101(Cr) framework. This bifunctionality assists to the sequential dehydrogenation step of 4-hydroxy-2-cyclopentenone conversion into cyclopentanone in a one-pot process.

The transformation of a carbonyl group of vanillin (a large component of pyrolysis oil derived from the lignin fraction) into a methyl group could proceed via two paths: (1) direct hydrogenolysis and (2) hydrogenation/hydrogenolysis. For Pd@MIL-101(Cr) nanohybrids, it was found that both the realization of a specific pathway of vanillin hydrodeoxygenation and the selectivity level depended critically on the dispersion of Pd NPs $(0.5-5.0 \mathrm{~nm})$ [109]. The catalyst with a higher dispersion of Pd NPs demonstrates an enhanced performance in vanillin conversion $(49 \%, 1 \mathrm{~h})$ with a $100 \%$ selectivity into 2-methoxy-4-methylphenol (2 bar, $\mathrm{H}_{2}, 348 \mathrm{~K}$ ). However, Pd@MIL-101 with larger Pd NPs produced a significant amount of vanillin alcohol associated with a low yield of 2-methoxy-4-methylphenol under the same conditions according to pathway (2). The higher activity of the first catalyst Pd@MIL-101(Cr) is attributed to the smaller size of Pd NPs. Its outstanding selectivity to 2-methoxy-4-methylphenol can be explained by the steric hindrance and strong interaction of vanillin alcohol caused by the encapsulation of ultrafine Pd NPs within the MIL-101(Cr) host matrix. This results in the elimination of the reaction pathway (2) [104].

An efficient Pd-containing heterogeneous catalyst based on amino-modified $\mathrm{NH}_{2} \mathrm{MIL}-101(\mathrm{Cr})$ with aminoterephthalate linkers $\left(\mathrm{Pd} @ \mathrm{NH}_{2} \mathrm{MIL}-101(\mathrm{Al})\right)$ was prepared by using a direct anionic exchange approach and subsequent gentle reduction. The uniform dispersion of Pd nanoparticles in the $\mathrm{NH}_{2} \mathrm{MIL}-101(\mathrm{Cr})$ matrix composite is attributed to the presence of amino groups in the parent $\mathrm{NH}_{2} \mathrm{MIL}-101(\mathrm{Cr})$ framework. This multifunctional catalyst $\mathrm{Pd} @ \mathrm{NH}_{2} \mathrm{MIL}-101(\mathrm{Cr})$ promotes the selective hydrogenation of biomass-based furfural to tetrahydrofurfuryl alcohol under green conditions (water media, $40^{\circ} \mathrm{C}$ ). A complete hydrogenation of furfural is achieved at a low temperature with the selectivity to tetrahydrofurfuryl alcohol close to $100 \%$. Such an almost absolute selectivity is caused by the improvement of hydrogen bonding interactions between the intermediate furfuryl alcohol and the amine-functionalized host matrix. These interactions assist to the further hydrogenation of furfuryl alcohol to tetrahydrofurfuryl alcohol coordinated with Pd sites [128].

The amino-modified mesoporous $\mathrm{NH}_{2}$-MIL-101(Al) metal organic framework based on $\mathrm{Al}^{3+}$ ions with the same texture and structural characteristics as MIL-101(Cr) and $\mathrm{NH}_{2}-\mathrm{MIL}-101(\mathrm{Cr})$ was also used for Pd nanoparticles embedding [129]. As in the case of $\mathrm{NH}_{2}-\mathrm{MIL}-101(\mathrm{Cr})$, the presence of free amine moieties in the frameworks of $\mathrm{NH}_{2}-\mathrm{MIL}-101(\mathrm{Al})$ plays a key role in the formation of homogeneous and well-dispersed palladium nanoparticles in the resulted Pd@ $\mathrm{NH}_{2}-\mathrm{MIL}-101(\mathrm{Al})$ nanocomposite. This catalyst was applied in selective hydrogenation of HMF. It was found that the amine-functionalized $\mathrm{NH}_{2}$-MIL-101(Al) material shows a preferential adsorption to hydrogenation of intermediate 2,5-dihydroxymethylfuran (DHMF) than in the case of HMF as a reactant. It is explained by a more hydrophilic nature of DHMF as well as by improved hydrogen bonding interactions between DHMF and the $\mathrm{NH}_{2}$-MIL-101(Al) matrix. This bonding promotes a further hydrogenation of DHMF to 2,5-dihydroxymethyltetrahydrofuran (DHMTHF) upon the in-situ formation of DHMF over $3 \% \mathrm{Pd} @ \mathrm{NH}_{2}-\mathrm{MIL}-101(\mathrm{Al})$. The study results reveal that the high selectivity toward DHMTHF ( 96\%) is related to the synergy between the Pd sites and the amine moiety of the $\mathrm{NH}_{2}-\mathrm{MIL}-101$ (Al) support.

$\mathrm{Pt}$ nanoparticles were encapsulated in a UiO-67(Zr) metal-organic framework via a linker design method [130]. It was found that embedding Pt NPs $(4-6 \mathrm{~nm})$ in the UiO-67 matrix can enhance the hydrogen adsorption capacity of UiO-67 $\left(50{ }^{\circ} \mathrm{C}, \mathrm{PH}_{2}=1 \mathrm{~atm}\right)$. This characteristic assists the implementation of the hydrogenation processes over Pt NPs@UiO-67 nanohybrids, which were studied in the oxidation and hydrogenation of HMF in aqueous solutions $\left(90^{\circ} \mathrm{C}\right)$. The Pt NPs@UiO-67 catalyst displays a higher activity and selectivity in hydrogenation than in oxidation under the same conditions (except the gas atmosphere), that is, conversion of HMF: 31.2\% (hydrogenation) versus $13.6 \%$ (oxidation). Additionally, the Pt NPs@UiO-67 nanohybrid retains its crystalline structure in the catalytic cycles. 
A bifunctional catalyst $\mathrm{Ru} / @ \mathrm{SO}_{3} \mathrm{H}-\mathrm{UiO}-66(\mathrm{Zr})$ was prepared by depositing Ru nanoparticles on a sulfonic acid-functionalized $\mathrm{Zr}$-based metal-organic framework $\left(\mathrm{SO}_{3} \mathrm{H}-\mathrm{UiO}-66\right)$ [131]. Its efficiency has been proven in a high-yield one-pot upgrade strategy for converting biomass-derived methyl levulinate (ML) into $\gamma$-valerolactone (GVL) by obtaining a quantitative $(100 \%)$ yield of GVL $\left(80^{\circ} \mathrm{C}\right.$, $0.5 \mathrm{MPa} \mathrm{H}_{2}, 4 \mathrm{~h}$, aqueous media). In contrast, a very poor yield of GVL was achieved using a reference metal catalyst without any acidity (e.g., $\mathrm{Ru} / \mathrm{C}$ ). The catalytic activity and selectivity of the $\mathrm{Ru} @ \mathrm{SO}_{3} \mathrm{H}-\mathrm{UiO}-66(\mathrm{Zr})$ nanohybrid were significantly suppressed upon neutralization of its acidic sites. This fact confirms the essential role of the sulfonic groups of organic linkers in the $\mathrm{SO}_{3} \mathrm{H}-\mathrm{UiO}-66$ framework. This acid functionality promotes the intramolecular dealcoholation of the 4-hydroxypentanoic methyl ester (4-HPME) intermediate (Figure 12). The Ru@SO3H-UiO-66 catalyst was recyclable over five cycles without any activity loss.
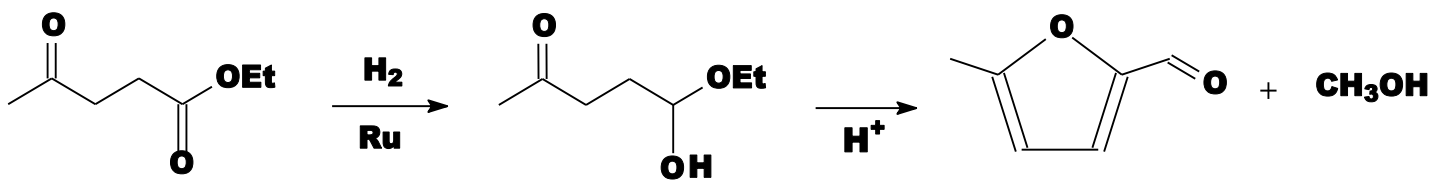

Figure 12. Cascade conversion of ML to GVL via hydrogenation followed by intramolecular dealcoholization. Modified with permission from reference [33]. Copyright 2016 Royal Society of Chemistry.

Two MIL-53(Al) (MIL-53(Al)-BDC and MIL-53(Al)-ADP) materials with the same topology but different linkers (aromatic and aliphatic ones) were prepared using 1,4-benzenedicarboxylic acid (BDC) and adipic acid (ADP) as organic building blocks, respectively [132]. The characterization results indicated that the MIL-53(Al)-BDC material showed a much higher surface area $\left(761 \mathrm{~m}^{2} \mathrm{~g}^{-1}\right)$ than its MIL-53(Al)-ADP analogue $\left(4 \mathrm{~m}^{2} \mathrm{~g}^{-1}\right)$. Therefore MIL-53(Al)-BDC showed a larger adsorption capacity towards furfural. Both materials were utilized for embedding Ru nanoparticles with a particle size in the range of 1-4 $\mathrm{nm}$ via a simple deposition-reduction method. Ru nanoparticles immobilized on MIL-53(Al) supports catalyze the catalytic hydrogenation of furfural under mild conditions $\left(20^{\circ} \mathrm{C}\right.$ and $0.5 \mathrm{MPa}_{2}$ ). Using the Ru@MIL-53(Al)-BDC catalyst, a full conversion of furfural and $100 \%$ selectivity to furfuryl alcohol was achieved.

As it was pointed out in the previous section, post-synthesis modification can assist to the MOF catalyst stability in harsh conditions of biomass processing. Liquid furanic hydrocarbons typically achieve a moderate product selectivity and yield at a high temperature and $\mathrm{H}_{2}$ pressure in multi-step processes over different catalysts. Using MOF based catalyst, a single-step catalytic process was developed for direct conversion of various saccharides into furanic biofuels such as 2,5-dimethylfuran and 2-methylfuran at a decreased temperature [133]. This process involved the transfer-hydrogenation over a Pd NPs-containing MIL-53(Al) matrix with high yields $(>95 \%)$ at 110-130 ${ }^{\circ} \mathrm{C}$. Hydride $\left(\mathrm{H}^{-}\right)$in polymethylhydrosiloxane (PMHS) serving as a green $\mathrm{H}$-donor did not interfere with upstream reactions (e.g., hydrolysis, isomerization and dehydration) for the in-situ formation of furanic aldehydes/alcohols from sugars. This H-donor facilitates selectively the subsequent hydrodeoxygenation of carbonyl and hydroxyl groups other than the furanic ring in one pot according to deuterium-labeling study. Coating with polydimethylsiloxane resulted in stability improvement of the Pd@MIL-53(Al) catalyst (Pd/MIL-53(Al)-P) during at least five consecutive cycles.

The critical impact of the support on the catalytic properties of the deposited metal nanoparticles is well established. The role of the compositional and structural properties of MOF host matrices in catalytic transformations of biomass was studied in [134]. Prototypical MOF-5 ( $\left.\mathrm{Zn}_{4} \mathrm{O}(\mathrm{BDC})_{3}\right)$ with $\mathrm{Zn}^{2+}$ ions and $\mathrm{Zr}$-containing $\mathrm{UiO}-66(\mathrm{Zr})$ and $\mathrm{NH}_{2}-\mathrm{UiO}-66(\mathrm{Zr})$ metal-organic frameworks were selected as host matrices for Pt nanoparticles embedding. The high BET surface area, the abilities for reversible adsorption and desorption and appropriate pore sizes of these frameworks assist to the efficient control of the Pt nanoparticles dispersion and prevent them from aggregating. The resulted Pt@MOFs 
(Pt@MOF-5, Pt@UiO-66 and Pt@UiO-66- $\mathrm{NH}_{2}$ ) nanohybrids were studied extensively in selective conversion of bio-furfural with ethanol into furan-2-acrolein. The studied Pt@MOFs catalysts retain the framework crystallinity in bio-furfural conversion. Using a Pt@MOF-5 catalyst, the maximum conversion (up to $84.1 \%$ ) of furan and the selectivity to furan-2-acrolein about $90.1 \%$ were achieved $\left(150{ }^{\circ} \mathrm{C}, 4 \mathrm{~h}, \mathrm{O}_{2}\right)$. Particularly, this selectivity is higher than the selectivity demonstrated by other catalytic systems, such as $\mathrm{Au} / \mathrm{Al}_{2} \mathrm{O}_{3}$. A pronounced cooperative effect between Pt nanoparticles and the framework structure is responsible for the enhanced performance of the Pt@MOF- 5 catalyst. On the contrary, the Pt@UiO-66(Zr) and Pt@NH $\mathrm{NH}_{2}-\mathrm{UiO}-66(\mathrm{Zr})$ catalytic systems show a lower conversion of furfural and poor selectivity.

The role of the organic linker nature and network topology of the MOF support on the catalytic performance of immobilized Ru NPs in the selective hydrogenation of furfural to furfuryl alcohol reaction was evaluated also by Q. Yuan et al. [135]. This is a challenging process, because the product can be further hydrogenated into tetrahydrofurfuryl alcohol and, also, because furfuryl alcohol can be polymerized. For this purpose, two series of Zr-based metal-organic frameworks, UiO-66(Zr), UiO-67(Zr), Zr6-NDC, MIL-140A, MIL-140B and MIL-140C with different organic linkers such as BDC, 2,6-naphthalenedicarboxylic acid (NDC) and BPDC were prepared. These MOF materials were used as host matrices for Ru nanoparticles. The catalytic behavior of the obtained Ru nanocomposites was studied in hydrogenation of furfural to furfuryl alcohol under mild conditions $\left(20^{\circ} \mathrm{C}, 5 \mathrm{bar}\right.$ $\mathrm{H}_{2}, 4 \mathrm{~h}$ ). In all cases, furfuryl alcohol was a single product. The activity order was (TOF in parentheses): Ru@UiO-66(Zr) $(11) \approx \mathrm{Ru} @ U \mathrm{UiO}-67(\mathrm{Zr})(11)>\mathrm{Ru} @ \mathrm{Zr}-\mathrm{NDC}(8.0) \approx \mathrm{Ru} @ \mathrm{MIL}-140 \mathrm{~B}$ (5.1), Ru@MIL-140A (4.8) > Ru@MIL-140C (2.1). So, the highest catalytic activity was exhibited by the Ru@UiO-66 nanohybrid. By using this catalyst, a 94.9\% yield of furfuryl alcohol can be achieved. This catalytic performance is close to that of Ru NPs on nanosized mesoporous $\mathrm{Zr}$-promoted silica. Importantly, the Ru@UiO-66( $\mathrm{Zr}$ ) catalyst could be reused in five consecutive reaction cycles without any activity loss. It is interesting to note that the activities of the Ru@UiO-66(Zr) and Ru@UiO-67(Zr) nanocomposites were almost similar, despite the much lower surface area of the UiO-67( $\mathrm{Zr})$ material as compared to UiO-66(Zr). The Ru NPs embedded in MIL-140 type matrices featured a lower activity than Ru-containing $\mathrm{UiO}$ materials. An explanation of the catalytic performance presented in this work involves the metal-support interactions. The organic moiety and the framework structure of the $\mathrm{Zr}$-MOF matrices have a profound effect on the reducibility of embedded Ru NPs. Too strong metal-support interactions result in hard reducibility of Ru nanoparticles.

A more sophisticated way is the simultaneous use of the different routes-post-synthesis and in-situ with additional functional molecules and species for the modification of one metal-organic framework. An example is post-synthesis modification of one more member of the mesoporous MIL-101(M) framework family-metal-organic framework $\mathrm{NH}_{2}-\mathrm{MIL}-101(\mathrm{Fe})$ with a neocuproine ligand through an amide (CONH) bond. Thus, modified neocuproine- $\mathrm{NH}_{2}-\mathrm{MIL}-101(\mathrm{Fe})$ was used as a host matrix for the immobilization of palladium and cerium nanoparticles [136]. The hybrid catalyst Pd-Ce@neocuproine- $\mathrm{NH}_{2}-\mathrm{MIL}-101(\mathrm{Fe})$ prepared by this way demonstrated a high activity in selective glycerol oxidation towards 1,3-dihydroxyacetone (DHA). The efficiency of Pd-Ce@neocuproine- $\mathrm{NH}_{2}-\mathrm{MIL}-101(\mathrm{Fe})$ in this conversion surpasses the efficiency of commercial $\mathrm{Pt}-\mathrm{Bi} / \mathrm{C}$ catalysts. The bimetallic catalyst is recyclable with keeping a sustainable activity.

The next illustration of the potential of modifying the MOF pore voids both by metal nanoparticles (post-synthesis modification) and functional molecules (encapsulation by in-situ strategy) is introducing phosphotungstic acid (PTA) clusters by an in-situ approach and Ru NPs encapsulation in a mesoporous MIL-100(Cr) host matrix $\left(\mathrm{Fe}_{3} \mathrm{O}(\mathrm{BTC})\right)$ [137]. The amount and strength of acid sites in the PTA@MIL-100(Cr) composite was achieved through the effective control of encapsulated PTA loading in MIL-100(Cr). This design and preparation method led to an appropriately functionalized Ru-PTA@MIL-100(Cr) material in terms of the Ru dispersion and their hydrogenation potential, on the one hand and the acid site density of PTA/MIL-100(Cr) (responsible for acid-catalyzed hydrolysis), on the other hand. The remarkable feature of this host-guest nanocomposite is its water-tolerance. 
While using this engineered Ru-PTA@MIL-100(Cr) catalyst, cellulose and cellobiose were selectively converted into sorbitol by hydrogenation in aqueous media. The correlation between the acid/metal balance of bifunctional catalysts Ru-PTA@MIL-100(Cr) and their performance in the conversion of cellulose and cellobiose into sugar alcohols was found. The ratio of acid site density to the number of Ru surface atoms (nA/nRu) of Ru-PTA@MIL-100(Cr) was used to evaluate the balance between hydrogenation and hydrolysis functions. The optimum balance between these two catalytic functions is $8.84<\mathrm{nA} / \mathrm{nRu}<12.90$. Its implementation allows the authors to achieve the maximum conversion of cellulose and cellobiose into hexitols. Under the optimal reaction conditions, a $63.2 \%$ yield of hexitols with a selectivity for sorbitol of $57.9 \%$ at the complete conversion of cellulose and a $97.1 \%$ yield of hexitols with a selectivity for sorbitol of $95.1 \%$ at the complete conversion of cellobiose were achieved with loadings of $3.2 \mathrm{wt} \%$ for Ru and $16.7 \mathrm{wt} \%$ for PTA. This research demonstrated efficiency of the rational design of acid/metal bifunctional catalysts for biomass conversion.

\subsection{MOF-Based Composites with Other Matrices}

As it was mentioned above, MOF materials in the form of bulk solids do not allow exploitation of their porosity, because they are generally prepared as insoluble microcrystalline powders featuring rather low mechanical and chemical stabilities, particularly in the acidic environment, which creates some obstacles for subsequent technological application. In particular, a low thermal stability and insufficient Brønsted acidity are the deficiencies of MOF materials [138]. These drawbacks would greatly limit their applications, particularly for reactions occurring at high temperatures and pressures, such as dehydration of carbohydrates. A prospective approach to improve some characteristics of MOF materials, including their hydrothermal stability, mechanical strength and shaping possibility and thereby realization of the potential of MOFs as porous host matrices is based on combining them with suitable solid supports affording functional composite materials.

The composites based on MOFs or derived from MOFs can be used successfully in biomass valorization that is carried out often in rather harsh conditions. To date, an extremely limited number of works reported the catalytic application of the composites based on MOFs and other type matrices in biomass upgrading processes. In particular, a supplement of MOF matrices by carbon-based materials makes active sites more hydrophobic, thus resulting in the protection of the coordination bonds from water molecules as well as increasing the affinity of active sites towards the organic reactants [139].

As it was pointed out in the previous sections, modifying metal-organic frameworks with sulfonic groups in order to use the obtained Brønsted acid-functionalized $\mathrm{SO}_{3} \mathrm{H}-\mathrm{MOF}$ catalysts for cellulose hydrolysis [137] can result in some stability decrease, particularly, in hydrothermal conditions [140]. Supporting the acid functionalized MOF material on an appropriate robust support is an efficient strategy for framework stability retaining. In Reference [141], hollow nanotubes (HNTs) $\left[\mathrm{Al}_{2} \mathrm{Si}_{2} \mathrm{O}_{5}(\mathrm{OH})_{4} \cdot 2 \mathrm{H}_{2} \mathrm{O}\right]$ modified with amphiphilic non-ionic polymer polyvinylpyrrolidone (PVP) were used for the deposition of a $\mathrm{SO}_{3} \mathrm{H}-\mathrm{UiO}-66(\mathrm{Zr})$ material with sulfonated linkers in order to obtain the stable composite catalyst with a potential application in HMF synthesis from sugars. These inorganic matrices with hollow tubular structure are composed of a 1:1 layered aluminosilicate and feature an enhanced mechanical strength [142].

The composite MOF-based catalysts PVP-HNTs@X-SO ${ }_{3} \mathrm{H}-\mathrm{UiO}-66(\mathrm{Zr})(\mathrm{X}=0.5,1,2,3$, where X stands for the amount of immobilized $\mathrm{SO}_{3} \mathrm{H}-\mathrm{UiO}-66(\mathrm{Zr})$ material) show both enhanced hydrothermal stability and catalytic performance in the transformation of fructose into HMF as compared to the $\mathrm{SO}_{3} \mathrm{H}-\mathrm{UiO}-66(\mathrm{Zr})$ matrix in the powder form. By varying the ratio of the inorganic $\mathrm{HNT}$ support and $\mathrm{SO}_{3} \mathrm{H}-\mathrm{UiO}-66(\mathrm{Zr})$, the Lewis and Brønsted acidity of the PVP-HNTs@X-SO ${ }_{3} \mathrm{H}-\mathrm{UiO}-66(\mathrm{Zr})$ composites can be precisely tuned. As a result, the $92.4 \%$ HMF yield was achieved over these bifunctional composite catalysts, which demonstrate also a high stability and can be reused at least five times without a significant activity loss.

Another example of the composite MOF-based catalyst for the sugar conversion is a combination of mesoporous MIL-101(Cr) matrix and a carbon material in the form of activated fly ash [138]. As it 
was mentioned above, the MIL-101(Cr) framework is one of the most widely studied MOF catalytic materials for biomass valorization. This matrix has been considered mainly as a promising catalyst for dehydration of sugars to furan and furfural derivatives. However, the absence of Brønsted acid sites in the MIL-101(Cr) framework has a negative impact on the furfural selectivity. Therefore, there is an urgent need to enhance the Brønsted acidity of this MOF catalyst.

The obtained composite material based on MIL-101(Cr) structure and fly-ash shows a high stability under severe hydrothermal conditions even in the acidic medium. Its catalytic performance was examined in the xylose dehydration into furfural. The furfural yield and selectivity of $71 \%$ and $80 \%$, respectively, were afforded over the MIL-101(Cr)-based composite. Its catalytic properties remain intact during ten consecutive reaction cycles. This catalytic performance is much better than the pristine MIL-101(Cr) matrix shows. It is proposed that an enhanced catalytic activity is mainly attributed to the synergy between the unsaturated Lewis acid sites $\left(\mathrm{Cr}^{3+}\right.$ ions) in the MIL-101(Cr) matrix and hydroxyl groups (Brønsted acid sites) of activated fly ash acting as Lewis acid centers.

Another way to introduce Brønsted acidity and additional Lewis acid sites to the MIL-101(Cr) structure and simultaneously improve its hydrothermal stability is the preparation of a composite material using mesoporous tin phosphate nanoparticles [87]. Tin phosphate has been selected as a composite component, because, it is hydrothermally stable and the $\mathrm{P}-\mathrm{OH}$ species act as strong Brønsted acid sites contributed to an enhanced selectivity towards furfural in the resulted composite. Simultaneously, the $\mathrm{Cr}^{3+}$ ions in the MIL-101(Cr) structure act in combination with $\mathrm{Sn}^{4+}$ ions imparting the Lewis acidity sites. As a result, this bifunctional composite catalyst is highly relevant to the furfural synthesis from sugars. It was justified by examination of its catalytic performance in the dehydration of xylose into furfural. The MIL-101(Cr)-based composite featured an improved hydrothermal stability and resistance to destruction in an acidic medium under dehydration conditions. On the contrary, the crystalline structure of the pure MIL-101(Cr) matrix degraded after 4 catalytic cycles in this process. The composite catalyst allows one to achieve an $86.7 \%$ furfural yield and $92.3 \%$ selectivity to the target product at a lower temperature $\left(150^{\circ} \mathrm{C}, 180 \mathrm{~min}\right)$. This furfural yield is higher than the MIL-101(Cr) matrix or tin phosphate can provide individually.

As it was mentioned above, the catalytic biomass upgrading comprises numerous competitive reactions such as hydrodeoxygenation (HDO), decarbonylation, decarboxylation, hydrogenation, hydrocracking, polymerization and reforming [143]. For these challenging processes, a non-trivial strategy is preferred in terms of the design of advanced catalytic systems. An example is rather sophisticated multifunctional catalysts elaborated for one-pot conversion of monosaccharides (fructose and glucose) into 2,5-DMF [144]. These heterogeneous systems, that is, 2.4\%Pd/UiO-66@SGO and 4.8\%Pd/UiO-66@SGO, were obtained by embedding Pd NPs in a UiO-66(Zr) matrix deposited on sulfonated graphene oxide (SGO). The Brønsted acid sites of sulfonated SGO carrier provides the fructose dehydration into $\mathrm{HMF}$, while the $\mathrm{Pd}$ nanoparticles catalyze the hydrogenolysis and hydrogenation of HMF to 2,5-DMF in the next steps. The composite materials catalyze efficiently sugars conversion affording a high 2,5-DMF yield of $70.5 \mathrm{~mol} \%$ with fructose and $45.3 \mathrm{~mol} \%$ yield of the target product using glucose as a reagent $\left(160^{\circ} \mathrm{C}, 1 \mathrm{MPa} \mathrm{H}_{2}, 3 \mathrm{~h}\right)$. These catalytic results surpass the previously reported ones. It is suggested that the enhanced fructose adsorption onto the composite catalyst surface can assist seriously to its conversion. This adsorption is improved by a synergistic effect of SGO matrix (Brønsted acid in a combination with hydrophilic surface) and deposited UiO-66(Zr) material (high porosity and surface area associated with strong acidity of Lewis sites ( $\mathrm{Zr}^{4+}$ ions) and Brønsted sites (hydroxyl Zr-OH species). Furthermore, the 4.8\% Pd/UiO-66@SGO catalyst is reusable and can be exploited during five catalytic cycles.

\subsection{MOF-Derived Hybrid Materials}

As a new class of porous materials, MOFs have recently been considered as ideal sacrificial templates for the preparation of various nanoporous carbons and metal or metal oxides nanoparticles because of their excellent properties such as ordered structures, high surface area and tunable 
functionality. The principal weaknesses of MOF materials (low thermal, hydrothermal and chemical stability) can be turned into an advantage by using their controlled thermal decomposition for in-situ nanoparticle generation embedded in carbon matrices [145]. While the confinement effect of MOF matrices provides a high dispersion of the metal/metal oxides nanoparticles throughout porous carbon, which is derived from the organic ligands of MOFs and the carbon matrix can stabilize the metal/metal oxide particles and prevent them from aggregation [146].

\subsection{MOF-Derived Carbon Materials}

When compared to porous materials synthesized by conventional methods, MOF-derived carbon nanostructures generally have improved catalytic activities and selectivities due to their larger surface areas (with well-defined and interconnected pore system) and easily tailored functionality [144]. A sustainable and highly efficient catalytic system in the form of Fe-Co alloy nanoparticles as hollow microspheres embedded in a carbon matrix was elaborated for direct transformation of HMF to demanded 2,5-diformylfuran (DFF) [147]. This magnetically separable FeCo/C nanohybrid was prepared by thermolysis at selected temperatures, that is, $500,600,700,800{ }^{\circ} \mathrm{C}$, using a bimetallic MIL-45b $\left(\left[\mathrm{M}_{3}(\mathrm{BTC})_{3}\right] \cdot 5 \mathrm{H}_{2} \mathrm{O}, \mathrm{M}=\mathrm{Co}^{2+}, \mathrm{Fe}^{2+}\right)$ material as a sacrificial template. The hollow Fe-Co nanoparticles with an average exterior diameter of $\sim 60 \mathrm{~nm}$ highly dispersed in the carbon matrix were obtained at the pyrolysis temperature of $\sim 500{ }^{\circ} \mathrm{C}$. Such specific nanoarchitecture has a pronounced impact on the $\mathrm{FeCo} / \mathrm{C}$ catalytic properties. In particular, the hollow structure of the nanoparticles provides the adsorption of HMF and quick desorption of the formed DFF from the catalyst surface. Thanks to specific textural and structural characteristics, the novel $\mathrm{FeCo} / \mathrm{C}$ catalyst with a non-noble active phase demonstrated a high activity and selectivity in the aerobic oxidation of HMF, affording DFF as the target product in a $>99 \%$ yield $\left(100{ }^{\circ} \mathrm{C}, 1 \mathrm{MPa} \mathrm{O}_{2}\right.$, toluene, $\left.6 \mathrm{~h}\right)$. This excellent performance is comparable to that of noble metal catalysts studied in this process under similar conditions. The $\mathrm{FeCo} / \mathrm{C}$ nanohybrid showed a good reusability during six runs without any activity loss.

As it was mentioned above, as a rule, biomass transformations into value-added products involve cascade reactions, which need very often alternating conditions. Catalysis by acidic sites in an inert atmosphere is used for sugars dehydration, while HMF oxidation proceeds with participation of molecular oxygen [77]. An example is the one-pot conversion of fructose to (DFF) via HMF as an intermediate. Up to date, the development of efficient one-pot strategies for fructose selective conversion into DFF is still challenging. An example to resolve this problem is a fabrication of a MOF-derived nanohybrid for one-pot conversion of fructose into DFF [148]. The hybrid catalyst was synthesized by pyrolysis using a Fe-containing metal-organic framework (MIL-88B, $\left(\mathrm{Fe}_{3} \mathrm{O}(\mathrm{BDC})_{3}\right)$ ) as a sacrificial template, a carbon precursor and $\mathrm{S}$ powder as a dopant. The obtained Fe-based catalyst had small quantities of acidic sulfur-derived functional groups with highly uniform octahedral $\mathrm{Fe}_{3} \mathrm{O}_{4}$ nanoparticles with exposed (111) crystal faces distributed homogeneously in the sulfur doped carbon matrix. The prepared $\mathrm{Fe}_{3} \mathrm{O}_{4} / \mathrm{C}-\mathrm{S}$ nanocomposite showed extremely high DFF yield (>99\%) from fructose. Its superior selectivity to DFF is related to the interactions of the low adsorption energy of DFF on $\mathrm{Fe}_{3} \mathrm{O}_{4}$ (111) crystal faces and the presence of a non-oxidized $\mathrm{S}$ dopant on the support, which makes the MIL-88B-derived catalyst less oxidative. The catalyst is magnetically separable after the reaction and can be reused over 6 runs without any activity loss.

A non-noble MOF-derived nanohybrid CuNi0.5@C was studied in furfural transformation to cyclopentanone [149]. This material was prepared by embedding CuNi bimetallic nanoparticles in the carbon matrix. The synthesis procedure involves a direct thermolysis of the HKUST-1 metal-organic framework with $\mathrm{Cu}^{2+}$ ions impregnated with nickel nitrate. At the molar ratio of nickel to copper around 0.5, the bimetallic CuNi0.5@C nanohybrid consists of very small copper and nickel nanoparticles (about $15 \mathrm{~nm}$ ) embedded in the carbon matrix. A pronounced confinement effect of the HKUST-1-derived porous carbon matrix preventing the aggregation of $\mathrm{Cu}$ and Ni NPs was observed in this study. Thanks to texture properties and highly dispersed metal nanoparticles, the CuNi0.5@C nanohybrid demonstrates an excellent catalytic performance, that is, $99.3 \%$ conversion 
of furfural and $96.9 \%$ yield of cyclopentanone $\left(130{ }^{\circ} \mathrm{C}, 5 \mathrm{~h}, 5 \mathrm{MPa}\right)$. This HKUST-1 derived hybrid catalytic material is quite reusable and shows no activity loss during four catalytic cycles.

The influence of the calcination temperature on the performance of other HKUST-1-derived catalytic carbon material was studied in [146]. Bimetallic non-noble CuCo@C nanohybrids with various molar ratios of cobalt to copper were prepared using the HKUST-1 metal-organic framework ions doped by Co via one-step thermal decomposition in a nitrogen atmosphere at temperatures ranging from $773 \mathrm{~K}$ to $1073 \mathrm{~K}$. The ordered porous structure and long distance in the $\mathrm{Cu}-\mathrm{Cu}$ dimer (as an inorganic building block) in the HKUST-1 framework assist to the uniform dispersion of cobalt ions in the metal-organic matrix [150]. Therefore, the obtained nanohybrids have highly dispersed mixed CuCo metal/metal oxide embedded species in a porous carbon matrix. CuCo@C catalytic materials were tested in selective hydrogenation of furfural to furfuryl alcohol. The optimal conditions for the catalyst preparation were evaluated in respect to the activity and selectivity. These conditions are characterized by the cobalt to copper molar ratio 0.4 and the calcination temperature $873 \mathrm{~K}$ (CuCo0.4@C-873 catalyst). In this case, a 98.7\% furfural conversion and 97.7\% furfuryl alcohol selectivity are achieved (ethanol, $413 \mathrm{~K}, \mathrm{PH}_{2} 3 \mathrm{MPa}$ ). These characteristics are among the best reported ones. This excellent catalytic performance is related to the small particle size (about $9 \mathrm{~nm}$ ) and the synergistic effect of copper and cobalt. Other important factors contributing to both the high conversion and selectivity are a relatively high surface area and porosity. It was found also that the HKUST-1-derived catalyst features a good stability and reusability in this process.

A magnetic Co-containing carbon nanocomposite (MCo@C) was prepared by carbonization of a CoPDA metal organic matrix with 2,6-pyridinedicarboxylate linkers and $\mathrm{Co}^{2+}$ ions [150]. This material is a porous carbon matrix with embedded highly dispersed Co NPs and it exhibits magnetic properties. The MCo@C nanocomposite with a high density of cobalt active sites demonstrates a sufficient catalytic activity in conversion of the lignin model compound, vanillyl alcohol (VAL) to vanillin (VN). The selectivities for $\mathrm{VN}$ were achieved as high as $99 \%$ and $100 \%$ depending on the oxidant type $-\mathrm{H}_{2} \mathrm{O}_{2}$ and air, respectively.

Another type of catalytic metal-free material with acid active sites for biomass processing was reported in [151]. A MOF-derived carbon (MDC) was prepared by direct pyrolysis of a -5 material as a carbonaceous precursor. Then $-\mathrm{SO}_{3} \mathrm{H}$ groups with Brønsted acidity were grafted onto the carbonaceous support in order to tailor its catalytic properties for HMF synthesis from sugars. The sulfonated carbon matrix with a hierarchical pore structure, $\mathrm{MDC}-\mathrm{SO}_{3} \mathrm{H}$, was examined as an acidic heterogeneous catalyst in the dehydration of fructose into HMF in an isopropanol-DMSO mixed solvent. It was found that the highest yield of HMF $(89.57 \%)$ was obtained $\left(120^{\circ} \mathrm{C}, 2 \mathrm{~h}\right)$ using $90 \mathrm{vol} \%$ isopropanol as the cosolvent in reaction media. The MOF- 5 derived carbonaceous catalyst operated during 5 reaction cycles without a loss of the catalytic activity.

\subsection{MOF-Derived Metal Nanostructures}

The upgrade method for biomass-derived oil is hydrotreatment over a solid catalyst at $250-450{ }^{\circ} \mathrm{C}$ and a high $\mathrm{H}_{2}$ pressure. Bifunctional transition metal catalysts supported on $\gamma-\mathrm{Al}_{2} \mathrm{O}_{3}$ (such as NiMo, CoMo and $\mathrm{CoW}$ ) in their oxidic, reduced, or sulfidic form are traditionally used in this process [152]. For this purpose, another type of MOF-derived nanostructures can be utilized. They are obtained by calcination of metal-organic frameworks in air thus affording metal oxides with a uniform dispersion.

An example of the relevance of MOFs-derived metal oxide in the catalytic biomass upgrading is glycerol conversion. Glycerol is one of the top 12 platform chemicals, it can be converted into value-added products including acrolein [153]. Commonly, the glycerol dehydration into acrolein is carried out over solid acid catalysts, usually $\gamma-\mathrm{Al}_{2} \mathrm{O}_{3}$ having acidic $\mathrm{OH}$ functionalities. The main challenge in the design of alumina catalysts for glycerol dehydration reaction lies in overcoming the low acrolein selectivity and obtaining a higher stability for industrial application [154]. With this goal, a MIL-96(Al) $\left(\mathrm{Al}_{12} \mathrm{O}(\mathrm{OH})_{18}\left(\mathrm{H}_{2} \mathrm{O}\right)_{3}\left(\mathrm{Al}_{2}(\mathrm{OH})_{4}\right)[\mathrm{BTC}]_{6} \cdot 24 \mathrm{H}_{2} \mathrm{O}\right)$ metal-organic framework with a honeycomb topology was selected as a precursor (template) to prepare nanoclusters (50-100 nm) 
of alumina $\gamma-\mathrm{Al}_{2} \mathrm{O}_{3}\left(\mathrm{M}-\mathrm{Al}_{2} \mathrm{O}_{3}\right)$ [155]. This $\mathrm{M}-\mathrm{Al}_{2} \mathrm{O}_{3}$ material was prepared by one-step calcination at $650{ }^{\circ} \mathrm{C}$ for the removal of the organic linker and transformation of MIL-96(Al) to $\gamma-\mathrm{Al}_{2} \mathrm{O}_{3}$. The catalytic performance of this $\mathrm{M}-\mathrm{Al}_{2} \mathrm{O}_{3}$ nanocomposite was tested in glycerol dehydration to acrolein. Compared with conventional bulk alumina [156] and nanorod alumina [157] prepared by traditional precipitation and dry gel methods, the $\mathrm{M}-\mathrm{Al}_{2} \mathrm{O}_{3}$ catalyst with a smaller particle size featured a higher activity with a conversion of glycerol over $\sim 80 \%$ and high acrolein selectivity $(74 \%)$ associated with stability during $200 \mathrm{~h}$. This efficient catalyst performance is explained by the specific architecture of MIL-96(Al)-derived acidic $\mathrm{M}-\mathrm{Al}_{2} \mathrm{O}_{3}$ alumina oxide characterized by the abundance of accessible acid sites due to the open porous system and ordered crystalline 3D structure of the MOF precursor.

An elegant way to overcome the most important drawback of the MOF structures, that is, the low thermal stability, was demonstrated in [143]. A Ni-containing MIL-77(Ni) metal-organic framework with glutarate linkers thermally decomposes under reaction conditions required for the hydrotreatment of biomass-derived oil. Accordingly, Ni nanoparticles $(\sim 100 \mathrm{~nm})$ were generated in-situ during the hydrotreatment of glycerol-solvolyzed lignocellulosic (LC) biomass over MIL-77(Ni) $\left(300{ }^{\circ} \mathrm{C}\right.$, $\mathrm{PH}_{2}-8 \mathrm{MPa}$ ) in a slurry reactor. MIL-77(Ni)- derived Ni nanoparticles showed a high hydrogenolysis activity in conversion of the biomass-derived oil into a polar and a non-polar phase with a significantly lower viscosity (60 min, MIL-77(Ni) loading above $3 \mathrm{wt} \%$ ). Kinetic modeling showed that the MIL-77(Ni)-derived active phase had a more than ten times higher mass activity for hydrogenolysis in comparison to commercially available $\mathrm{Ni} / \mathrm{SiO}_{2}-\mathrm{Al}_{2} \mathrm{O}_{3}$ with $\mathrm{Ni} \mathrm{NPs}$ with an average size $\sim 10 \mathrm{~nm}$. It was suggested that the ordered crystalline $3 \mathrm{D}$ structure of the metal organic precursor contributes significantly to the superiority of the catalytic performance of MIL-77(Ni)-derived Ni NPs by governing their size, shape and dispersion in the calcination process.

An efficient method for the controlled synthesis of $\mathrm{Cu} / \mathrm{ZnO}$ hybrid in the form of nanosized $\mathrm{ZnO}$ particles dotted on $\mathrm{Cu}$ was reported in Reference [158]. This strategy involves nanohybrid preparation by subsequent steps of the calcination and reduction using $\mathrm{Cu}(\mathrm{Zn})$-HKUST-1 isostructural metal-organic matrices with different $\mathrm{Cu}: \mathrm{Zn}$ ratios as precursor. The catalytic performance of the bimetallic $\mathrm{Cu} / \mathrm{ZnO}$ material was studied in a continuous process of hydrogenolysis of glycerol in a fixed-bed reactor. It was found that the interface between $\mathrm{Cu}$ and $\mathrm{ZnO}$ in the novel nanohybrid is of paramount importance regarding its catalytic properties, which depend also on the $\mathrm{Cu} Z \mathrm{Zn}$ ratio. The $\mathrm{Cu} 1.1 / \mathrm{ZnO}$ catalyst derived from the $\mathrm{Cu}_{1.1} \mathrm{Zn}_{1.9}(\mathrm{BTC})_{2} \cdot 9.4\left(\mathrm{H}_{2} \mathrm{O}\right)$ sacrificial matrix was more active and stable than $\mathrm{Cu} / \mathrm{ZnO}$ in the form of $\mathrm{ZnO}$ plates with supported $\mathrm{Cu}$ particles prepared by other procedures, that is, solid grinding and co-precipitation.

The reviewed literature data point out that the use of the different ways for the preparation of MOF-derived and MOF- based hybrid nanomaterials is an efficient strategy for the engineering of advanced catalysts for biomass processing. This approach allows one to involve much more prototypical MOF structures for the relevant catalyst design, than other methods, including the buil ding block choice and their post-synthesis modification. Such MOF structure versatility contributes more effectively to tailoring the activity and selectivity of the designed catalysts.

\section{Play with Physical Properties: Texture, Geometry and Morphology}

Besides versatile framework functionalities, MOF matrices offer outstanding physical properties such as a record large surface area and exceptionally high and simultaneously tunable porosity. In addition to rational design of the framework by imparting novel properties via post-synthesis tailoring and in-situ modification, another possibility is a simple choice of the appropriate structural and textural characteristics of MOF catalysts favorable for effective biomass valorization among the variety of the available and described structures.

The evaluation of the appropriate porous structure and favorable network topology can be illustrated by using the metal-organic framework MIL-53( $\mathrm{Al})$ ( $\mathrm{Al}(\mathrm{OH}) \mathrm{bdc}$, $\mathrm{bdc}=$ benzene-1,4-dicarboxylate) for the hydrolysis of carboxymethyl cellulose (CMC) to HMF in an aqueous medium. Due to its specific porous structure, the MIL-53(Al) material was used 
without any functionalization. This framework is built from infinite chains of corner-sharing $\mathrm{AlO}_{4}\left(\mu_{2}-\mathrm{OH}\right)_{2}$ octahedra making $1 \mathrm{D}$ lozenge-shaped channels accessible for substrate molecules [159]. The MIL-53(Al) material features isolated weak Brønsted and Lewis acid sites, lattice dynamic flexibility and a porous structure arranged as a system of $1 \mathrm{D}$ channels with the diameter about $\sim 8.5 \AA$ for the fully desolvated MIL-53(Al) $)_{\mathrm{ht}}$ modification, which allows fast diffusion of the reactants [160]. The MIL-53(Al) framework can also retain its crystallinity and permanent porosity without structural collapse in neutral and acidic aqueous solutions until $100{ }^{\circ} \mathrm{C}$ [161]. The hydrothermal stability of the MIL-53(Al) material contributes to achieving an HMF molar yield of $40.3 \%$ and total reducing sugar (TRS) molar yield of $54.2 \%\left(200{ }^{\circ} \mathrm{C}, 4 \mathrm{~h}\right.$, water) over this catalyst. Moreover, thanks to this tolerance, it is quite reusable and could be exploited three catalytic cycles with retaining almost the same activity level intact [162].

The introduction of a secondary pore system in order to create a hierarchical porous structure has been proven as an advantageous strategy in zeolite catalysis [163]. Recently, this approach was developed for modifying nanoporous MOF matrices [164-168]. This way of the rational design of MOF porous structures extends essentially application fields in catalysis by MOF materials.

A combined approach to catalyst design for biomass upgrading, which involves both tuning the porous structure of the pristine metal-organic framework to hierarchical one and scaling down this material to nanoparticles is reported in [169] taking esterification of glycerol with oleic acid into monoglycerides as an example. This process is a very challenging, because currently industrial monoglyceride production proceeds at high temperatures $\left(220-250{ }^{\circ} \mathrm{C}\right)$ with the use of a basic homogeneous catalyst. Therefore, some substantial drawbacks are associated with esterification of glycerol under these conditions, that is, limited monoglyceride selectivity along with the formation of di- and triglyceride side products and soap. Moreover, the high reaction temperature has a negative impact on the taste, aroma and color of the final product. Developing a heterogeneous catalytic process at a lower temperature for selective monoglyceride production is a major scientific challenge.

To resolve this problem, a catalyst presenting a hierarchical zeolitic imidazolate framework (ZIF-8) in nanocrystalline form, and featuring a capability to operate efficiently at a moderate temperature $\left(150^{\circ} \mathrm{C}\right)$, was developed. Ii is important to note that the ZIF-8 nanomaterial becomes hierarchically structured in the esterification course, that is, a local transformation of the zeolite imidazolate framework takes place under reaction conditions. Although the structure integrity of the recovered ZIF-8 catalyst was confirmed by XRD, significant alteration of the pore structure was observed with the formation of internal cavities. The presence of mesopores was confirmed with $\mathrm{N}_{2}$ adsorption revealing a Type IV isotherm with a hysteresis loop superimposed on the original Type 1 isotherm. The morphological and textural changes are more significant than it would be expected based on the relatively small quantities of $\mathrm{Zn}$ leaching. It was suggested that a simple pretreatment of the ZIF-8 material with oleic acid before the catalytic process could result in hierarchization, supplementing the other known strategies such as surfactant-templated synthesis [170,171], the use of mixed linkers [172], or vapor assisted crystallization [173].

The advantages of the hierarchical porous system were demonstrated also in [87]. This work has been discussed in the previous section and deals with two hierarchically porous NUS-6(Zr) and NUS-6(Hf) structures possessing a unique porous structure composed of coexisting micropores (0.5, 0.7 and $1.4 \mathrm{~nm}$ ) and mesopores $(4 \mathrm{~nm})$ framed with pending sulfonic groups. The hierarchical porosity contributes to the high selectivity of the NUS-6 catalytic materials in dehydration of fructose to HMF thanks to appropriate pore sizes, which can suppress the undesirable side reactions due to the geometry factor (or molecular sieving properties).

\section{An Outlook and Perspectives}

Obviously, the main goal of the design of the heterogeneous catalyst is their application in industrial processes. To date numerous studies have aimed to demonstrate that MOF materials can exhibit activity and stability that are high enough from a practical point of view [34]. This applies in 
full to the MOF based catalysts designed for the biomass conversion. In this context, the following critical points should be taken into account.

1. Comparison with other "traditional" catalytic systems;

2. Energy efficiency;

3. Resource and cost economy and optimization;

4. Relevance to Green chemistry and sustainable development.

As highly ordered nanoporous materials, MOFs are compared often with zeolites and silicoaluminophosphates in respect to adsorption and catalysis. The contemporary literature shows that MOFs catalysts are not only competitive to zeolites as the most perspective heterogeneous systems in chemical processes of industrial importance but in some cases even surpass them in the catalytic performance. It is highlighted that, in general, liquid-phase processes (and biomass valorization comprises mostly liquid-phase reactions) are most suitable for MOF catalysts as compared to gas phase reactions that are mostly catalyzed by zeolites.

Perhaps, it is plausible to say that the selectivity plays a more important role than the activity in catalysis. MOF materials and MOF-based hybrids offer the most precise and efficient selectivity control than other solid acid catalysts. An illustrative example is the phosphate modified Zr-based NU-1000 matrix (discussed above), which shows an enhanced selectivity in glucose conversion into HMF [89]. Simultaneously, the suppression of the side intermolecular condensation of glucose/fructose/HMF takes place. Noteworthy, such a selectivity increase is an intrinsic NU-1000 metal-organic framework property, because its inorganic counterpart, similarly modified bulk zirconia with acid sites of the same strength of the acid sites does not display a selectivity increase.

An example of the superiority of the MOF catalysts in the selectivity terms is the application of other $\mathrm{Zr}$-based frameworks, namely, $\mathrm{UiO}-66(\mathrm{Zr})$ and $\mathrm{NH}_{2}$-UiO-66(Zr) materials (see above) in levulinic acid esterification into ethyl levulinate [76]. These catalysts show a selectivity, which surpasses the selectivity of zeolites and supported heteropolyacids. Ii is important to note that Zr-based MOF catalytic materials, such as the NU-1000 and UiO-66(Zr) frameworks in addition to the high selectivity, demonstrate a high productivity and low cost reusability and regenerability [141]. Importantly, they are synthesized from non-expensive and commercially available reagents in a green solvent, that is, water, under rather mild conditions.

As to MOF-based hybrid catalytic materials, we can consider an example concerning M NPs embedded in metal-organic matrices. Biomass valorization involves often a hydrogenation step. It was demonstrated that MOF carriers for metal NPs can also serve as effective selectivity regulators for supported catalysts in biomass upgrading via both the confinement effect of the framework and a number of specific metal-support interactions provided by intrinsic host matrix properties.

As it was pointed out in the previous sections, the use of MOF matrices as catalytic materials allows one to develop new routes of synthesis of a large variety of valuable chemicals and products from biomass sources by the full exploitation of MOF characteristic features, that is, a high surface area, tunable pore sizes and tailored chemical properties by functionalization of the organic linkers, inorganic nodes and pore voids as well as bifunctional or even multifunctional nature. These properties contribute to the achievement (in some extent) by MOFs of the efficiency of the bio-catalysts-enzymes. An example is an interesting and efficient strategy involving an association of the catalytic properties of MOF matrices and their molecular recognition capability. Noteworthy, molecular recognition processes involving sugars may be crucial for the selective synthesis of glucose from biomass-based feedstock via cellulose depolymerization, as currently accomplished by enzymes (i.e., cellulases). In this way, MOF catalysts can show an enhanced performance due to a cooperative effect. The NU-1000 catalytic material mentioned above demonstrates an excellent adsorption of sugar dimers, such as cellobiose and lactose from aqueous solutions, while completely excluding the adsorption of the monomer glucose [174]. These properties allow one the application of MOF catalysts in the selective 
biomass catalytic upgrading through multistep processes starting from crude feedstock like cellulose and lignocellulose.

Another abundant biomass feedstock is lignin, which is composed of aliphatic and phenolic units connected through aryl ether and carbon-carbon bonds. Catalytic hydrogenolysis is an efficient way for lignin valorization into value added chemicals but very challenging as well, therefore solving this problem requires new approaches. The development of effective catalysts for controlled lignin depolymerization on a technical scale still remains very relevant. Recently, MOF catalysts have been proven as a promising alternative to traditional catalysts for this process. In particular, in addition to exceptional features of MOF materials, they have the pores larger than other solid acid catalysts, which can accommodate relatively large reagents, intermediates and products of the valorization of the biomass, as well as lignin fragments, in particular. The isostructural IRMOF-74 frameworks were selected as catalysts for lignin valorization thanks to particular properties, such as framework robustness and thermal and chemical stability [175]. In addition, the tunable pore size of the Mg-IRMOF-74(I) and Mg-IRMOF-74(II) frameworks contributes to accommodation of a range of lignin-derived fragments and molecules.

Noteworthy, the utilization of MOF-based catalytic materials for biomass valorization allows one to reduce the process temperature and accomplish it in a greener or energy-saving manner. Along this trend, Mg-IRMOF-74(I) and Mg-IRMOF-74(II) systems show a high activity in catalytic C-O bond cleavage to the corresponding hydrocarbons and phenols under mild conditions, such as $1 \mathrm{MPa}$ hydrogen pressure and at unprecedentedly low temperature (for lignin depolymerization) $-120^{\circ} \mathrm{C}$. These MOF-based catalysts show also a high selectivity, which is associated with their recycling possibility and pushes them into the leader among prospective lignin valorization catalysts.

It was pointed out that the synthesis of a number of target MOF structures used most often for biomass valorization is not expensive. Moreover, the cost of these syntheses is paid back with interest due to the possibility of the implementation of one-pot cascade, tandem and domino processes relevant to biomass valorization over appropriate multifunctional MOF-based catalysts. Such implementation of the cascade reactions provides an efficient strategy for process intensification and material economy, allowing one to reduce consumption of energy and solvents as well as to minimize the wastes [176]. Thus, the possibility to have or create active sites of different nature, sometimes controversial (acid and basic sites in the same catalyst) can make the biomass valorization processes more energy-saving and greener.

Thus, the next steps in order to adapt MOF-based catalysts to industrial requirements relevant to biomass valorization processes are the reduction of the synthesis expenses and the further improvement of the catalyst stability and reusability/recyclability. A sustainability aspect related to the most cited MOF catalytic materials, such as MIL-101(Cr), HKUST-1 and UIO-66(Zr) widely studied in biomass valorization is an elucidation of the possibility of their densification for shaping and pelletization under various pressures without porosity and activity loss [177]. So, even there is still a long way to the eventual commercialization, especially in terms of the regeneration, reproducibility and production scale-up, the perspectives look really promising.

\section{Conclusions}

The literature data show that the exploitation of MOF structures for catalytic biomass processing into value-added products has started very recently, in 2010s. However, the obtained experimental results revealed a high potential in these cascade processes. The main benefits of the usage of MOF based catalytic materials is related to significant activity and selectivity improvement in some cases as well as reaction temperature decrease or even an implementation of one-pot processes instead of multi-step ones. In this relation, some MOF-based catalytic materials demonstrate a superiority over other solid acid catalysts, first at all, zeolites and the number of such examples is still growing.

Noteworthy, catalytic biomass valorization is one of the most fascinating potential applications of MOF materials. This area provides a huge field of the research activity relevant to various tuned MOF 
structures for cascade processes of biomass processes. It is of paramount importance from academic and practical point of view. In this way, a researcher can meet a number of challenging and non-trivial tasks to be resolved. For instance, it is controllable creation of different active sites with various content and appropriate accessibility, density and dispersion in one catalytic material that contributes to precise tailoring of the catalytic performance. With this goal, all methods that introduce the activity can be combined. For this purpose, an involvement of all efficient synthesis tools for the design of catalytic materials based on the comprehensive analysis of the MOF structure may be efficient.

The particular prospects are related to the development of the MOF based hybrid materials. MOF structures provide a possibility to introduce Lewis and Brønsted acid sites, metal nanoparticles and polyoxametallates in MOF pores. Another possibility is a combination of MOF structures with other materials, such as aluminosilicates and carbons as well as preparation of the MOF-derived nanostructures, such as carbonaceous matrices and metal oxide clusters. A vector is the implementation of an integrated approach to the design of new catalysts based on MOFs. The modification of MOF materials is directed towards both their catalytic performance enhancement and improvement of their hydrothermal stability and reusability.

Tailoring of the MOF porous structure and crystal dispersion deserves a particular attention in context of catalytic properties control. For instance, using MOF materials with an hierarchical pore structure allows one to manage the mass-transfer processes and contribute to extension of reagent variety as well as achieving a high process selectivity thanks to specific molecular-sieving properties. In case of exploitation of nanoscale MOF catalytic materials, minimizing the limitations of internal diffusion as well as creation of the specific surrounding of the active sites are possible. In this way, the synergy or cooperative effects between outer and inner surface characteristics and interesting interfacial properties can arise. Therefore, an associate task is a development of efficient synthesis methods allowing one to control the size and morphology of the catalytic MOF materials on the nanoscale as well as creation of MOF matrices with an hierarchical porous structure.

An efficient strategy will be also a search of the novel components for MOF based catalytic material (in addition to metal nanoparticles and polyoxometallates). For instance, enzyme/MOF hybrids (proposed by Chen et al. [36]) may provide an efficient cooperation between unique advantages of the pristine metal-organic matrices and the superior performance of enzymes in crude biomass transformation, such as carbohydrates depolymerization.

Finely, an important research focus remains the synthesis of highly porous and simultaneously robust and hydrothermally and chemically stable new MOF structures fitted for practical application fields, including catalytic biomass conversion, formulated by O. M. Yaghi twenty years ago.

A progress in achieving the formulated targets will allow one to consider MOF matrices and MOF-based materials with a greater confidence as heterogeneous catalytic systems of preferential choice of 21st century.

Funding: This research received no external funding.

Acknowledgments: The work was carried out with a financial support from the Ministry of Education and Science of the Russian Federation in the framework of Increase Competitiveness Program of NUST «MISiS» (No. K2-2017-011) in the part related to catalytic aspects of the review and to Russian Science Foundation (grant no. 17-13-01526) in the part related to the structural aspects.

Conflicts of Interest: The authors declare no conflict of interest.

\section{References}

1. Bhanja, P.; Bhaumik, A. Porous nanomaterials as green catalyst for the conversion of biomass to bioenergy. Fuel 2016, 185, 432-441. [CrossRef]

2. De, S.; Saha, B.; Luque, R. Hydrodeoxygenation processes: Advances on catalytic transformations of biomass-derived platform chemical into hydrocarbon fuels. Bioresour. Technol. 2015, 178, 108-118. [CrossRef] [PubMed] 
3. Jiang, Y.; Wang, X.; Cao, Q.; Dong, L.; Guan, J.; Mu, X. Sustainable Production of Bulk Chemicals; Xian, M., Ed.; Springer Science + Business Media: Dordrecht, The Netherlands, 2016. [CrossRef]

4. Climent, M.J.; Corma, A.; Iborra, S. Conversion of biomass platform molecules into fuel additives and liquid hydrocarbon fuels. Green Chem. 2014, 16, 516-547. [CrossRef]

5. Delidovich, I.; Leonhard, K.; Palkovits, R. Cellulose and hemicellulose valorization: An integrated challenge of catalysis and reaction engineering. Energy Environ. Sci. 2014, 7, 2803-2830. [CrossRef]

6. Chughtai, A.H.; Ahmad, N.; Younus, H.A.; Laypkov, A.; Verpoort, F. Metal-organic frameworks: Versatile heterogeneous catalysts for efficient catalytic organic transformations. Chem. Soc. Rev. 2015, 44, 6804-6849. [CrossRef] [PubMed]

7. Agarwala, B.; Kailasamb, K.; Sangwana, R.S.; Elumalai, S. Traversing the history of solid catalysts for heterogeneous synthesis of 5-hydroxymethylfurfural from carbohydrate sugars: A review. Renew. Sustain. Energy Rev. 2018, 82, 2408-2425. [CrossRef]

8. Sotelo-Boyas, R.; Trejo-Zarraga, F.; Hernandez-Loyo, F.d.J. Hydroconversion of Triglycerides into Green Liquid Fuels. In Hydrogenation; Karam, Y., Ed.; IntechOpen (Open Access), IntechOpen Limited: London, UK, 2012; pp. 188-216, Chapter 8, ISBN 978-953-51-0785-9.

9. Rodrigues, A.; Bordado, J.C.; Galhano dos Santos, R. Upgrading the glycerol from biodiesel production as a source of energy carriers and chemicals-A technological review for three chemical pathways. Energies 2017, 10, 1817. [CrossRef]

10. Melero, J.A.; Iglesias, J.; Morales, G.; Paniagua, M. Chemical routes for the conversion of cellulosic platform molecules into high-energy-density biofuels. Chapter 13. In Handbook of Biofuels Production, 2nd ed.; Carol, R.L., Karen, L., Clark, W.J., Eds.; Elsevier: Amsterdam, The Netherlands, 2016; pp. 359-388, ISBN 978-0-08-100455-5.

11. Sanders, J.P.M.; Clark, J.H.; Harmsen, G.J.; Heeres, H.J.; Heijnen, J.J.; Kersten, S.R.A.; van Swaaij, W.P.M.; Moulijn, J.A. Process intensification in the future production of base chemicals from biomass. Chem. Eng. Process. 2012, 51, 117-136. [CrossRef]

12. Besson, M.; Gallezot, P.; Pinel, C. Conversion of biomass into chemicals over metal catalysts. Chem. Rev. 2014, 114, 1827-1870. [CrossRef] [PubMed]

13. Herbst, A.; Janiak, C. MOF catalysts in biomass upgrading towards value-added fine chemicals. CrystEngComm 2017, 19, 4092-4117. [CrossRef]

14. Hara, M.; Nakajima, K.; Kamata, K. Recent progress in the development of solid catalysts for biomass conversion into high value-added chemicals. Sci. Technol. Adv. Mater. 2015, 16, 034903. [CrossRef] [PubMed]

15. Fechete, I.; Wang, Y.; Vedrine, J.C. The past, present and future of heterogeneous catalysis. Catal. Today 2012, 189, 2-27. [CrossRef]

16. Li, H.; Fang, Z.; Smith, R.L., Jr.; Yang, S. Efficient valorization of biomass to biofuels with bifunctional solid catalytic materials. Prog. Energy Combust. Sci. 2016, 55, 98-194. [CrossRef]

17. Farrusseng, D.; Aguado, S.; Pinel, C. Metal-organic frameworks: opportunities for catalysis. Angew. Chem. Int. Ed. 2009, 48, 7502-7513. [CrossRef] [PubMed]

18. Garcia-Garcia, P.; Müller, M.; Corma, A. MOF catalysis in relation to their homogeneous counterparts and conventional solid catalysts. Chem. Sci. 2014, 5, 2979-3007. [CrossRef]

19. Gascon, J.; Corma, A.; Kapteijn, F.; Llabres, I.; Xamena, F.X. Metal organic framework catalysis: Quo vadis? ACS Catal. 2014, 4, 361-378. [CrossRef]

20. Liu, J.; Chen, L.; Cui, H.; Zhang, J.; Zhang, L.; Su, C.Y. Applications of metal-organic frameworks in heterogeneous supramolecular catalysis. Chem. Soc. Rev. 2014, 43, 6011-6061. [CrossRef] [PubMed]

21. Zhu, L.; Liu, X.Q.; Jiang, H.L.; Sun, L.B. Metal-organic frameworks for heterogeneous basic catalysis. Chem. Rev. 2017, 117, 8129-8176. [CrossRef] [PubMed]

22. Huang, Y.B.; Liang, J.; Wang, X.S.; Cao, R. Multifunctional metal-organic framework catalysts: synergistic catalysis and tandem reactions. Chem Soc. Rev. 2017, 46, 126-157. [CrossRef] [PubMed]

23. Zhou, H.C.; Long, J.R.; Yaghi, O.M. Introduction to metal-organic frameworks. Chem. Rev. 2012, 112, 673-674. [CrossRef] [PubMed]

24. Férey, G. Hybrid porous solids: Past, present, future. Chem. Soc. Rev. 2008, 37, 191-214. [CrossRef] [PubMed]

25. Rowsell, J.L.C.; Yaghi, O.M. Metal-organic frameworks: A new class of porous materials. Micropor. Mesopor. Mater. 2004, 73, 3-14. [CrossRef] 
26. Pintado-Sierra, M.; Rasero-Almansa, A.M.; Corma, A.; Iglesias, M.; Sanchez, F. Bifunctional iridium-(2aminoterephthalate)-Zr-MOF chemoselective catalyst for the synthesis of secondary amines by one-pot three-step cascade reaction. J. Catal. 2013, 299, 137-145. [CrossRef]

27. Long, J.R.; Yaghi, O.M. The pervasive chemistry of metal-organic frameworks. Chem. Soc. Rev. 2009, 38, 1213-1214. [CrossRef] [PubMed]

28. Furukawa, H.; Cordova, K.E.; O'Keeffe, M.; Yaghi, O.M. The chemistry and applications of metal-organic frameworks. Science 2013, 341, 1230444. [CrossRef] [PubMed]

29. Lee, J.Y.; Farha, O.K.; Roberts, J.; Schedt, K.A.; Nguen, S.B.T.; Hupp, J.T. Metal-organic framework materials as catalysts. Chem. Soc. Rev. 2009, 38, 1450-1459. [CrossRef] [PubMed]

30. Isaeva, V.I.; Kustov, L.M. The application of metal-organic frameworks in catalysis. Petrol. Chem. 2010, 50, 167-180. [CrossRef]

31. Jiao, L.; Wang, Y.; Jiang, H.L.; Xu, Q. Metal-organic frameworks as platforms for catalytic applications. Adv. Mater. 2017, 1703663. [CrossRef] [PubMed]

32. Xu, W.; Thapa, K.B.; Ju, Q.; Fang, Z.; Huang, W. Heterogeneous catalysts based on mesoporous metal-organic frameworks. Coord. Chem Rev. 2017. [CrossRef]

33. Dhakshinamoorthy, A.; Asiri, A.M.; Garcia, H. Mixed-metal or mixed-linker metal organic frameworks as heterogeneous catalysts. Catal. Sci. Technol. 2016, 6, 5238-5261. [CrossRef]

34. Dhakshinamoorthy, A.; Asiri, A.M.; Garcia, H. Tuneable nature of metal organic frameworks as heterogeneous solid catalysts for alcohol oxidation. Chem. Commun. 2017, 53, 10851-10869. [CrossRef] [PubMed]

35. Corma, A.; Garcia, H.; Llabrés i Xamena, F.X. Engineering metal organic frameworks (MOFs) for heterogeneous catalysis. Chem. Rev. 2010, 110, 4606-4655. [CrossRef] [PubMed]

36. Chen, J.; Shen, K.; Li, Y. Greening the processes of metal-organic framework synthesis and their use in sustainable catalysis. ChemSusChem 2017, 10, 3165-3187. [CrossRef] [PubMed]

37. Wu, P.D.; Zhao, M. Incorporation of molecular catalysts in metal-organic frameworks for highly efficient heterogeneous catalysis. Adv. Mater. 2017, 29, 1605446. [CrossRef] [PubMed]

38. Zhou, T.; Du, Y.; Borgna, A.; Hong, J.; Wang, Y.; Han, J.; Zhang, W.; Xu, R. Post-synthesis modification of a metal-organic framework to construct a bifunctional photocatalyst for hydrogen production. Energy Environ. Sci. 2013, 6, 3229-3234. [CrossRef]

39. Lin, Y.; Kong, C.; Chen, L. Amine-functionalized metal-organic frameworks: Structure, synthesis and applications. RSC Adv. 2016, 6, 32598-32614. [CrossRef]

40. Dhakshinamoorthy, A.; Asiri, A.M.; Garcia, H. Organic frameworks as versatile hosts of Au nanoparticles in heterogeneous catalysis. ACS Catal. 2017, 7, 2896-2919. [CrossRef]

41. Falcaro, P.; Yazdi, A.; Imaz, I.; Furukawa, S.; Maspoch, D.; Ameloot, R.; Evans, J.D.; Doonan, C.J. Application of metal and metal oxide nanoparticles@MOFs. Coord. Chem. Rev. 2016, 307, 237-254. [CrossRef]

42. An, B.; Zeng, L.; Jia, M.; Li, Z.; Lin, Z.; Song, Y.; Zhou, Y.; Cheng, J.; Cheng, W.; Lin, W. Molecular iridium complexes in metal-organic frameworks catalyze $\mathrm{CO}_{2}$ hydrogenation via concerted proton and hydride transfer. J. Am. Chem. Soc. 2017, 139, 17747-17750. [CrossRef] [PubMed]

43. Corma, A. State of the art and future challenges of zeolites as catalysts. J. Catal. 2003, 216, 298-312. [CrossRef]

44. De Azevedo, D.C.S.; Cardoso, D.M.; Fraga, A.; Pastore, H.O. Zeolites for a sustainable world. Microporous Mesoporous Mater. 2017, 254, 1-2. [CrossRef]

45. Tafipolsky, M.; Amirjalayer, S.; Schmid, R. Atomistic theoretical models for nanoporous hybrid materials. Microporous Mesoporous Mater. 2010, 129, 304-318. [CrossRef]

46. Liang, J.; Liang, Z.; Zou, R.; Zhao, Y. Heterogeneous catalysis in zeolites, mesoporous silica, and metalorganic frameworks. Adv. Mater. 2017, 29, 1701139. [CrossRef] [PubMed]

47. Wang, Z.Q.; Cohen, S.M. Postsynthetic modification of metal-organic frameworks. Chem. Soc. Rev. 2009, 38, 1315-1329. [CrossRef] [PubMed]

48. Hwang, K.; Hong, D.Y.; Chang, J.S.; Jhung, S.H.; Seo, Y.K.; Kim, J.; Vimont, A.; Daturi, M.; Serre, C.; Férey, G. Amine grafting on coordinatively unsaturated metal centers of MOFs: Consequences for catalysis and metal encapsulation. Angew. Chem. Int. Ed. 2010, 47, 4144-4148. [CrossRef] [PubMed]

49. Müller, M.; Devaux, A.; Yang, C.H.; De Cola, L.; Fischer, R.A. Highly emissive metal-organic framework composites by host-guest chemistry. Photochem. Photobiol. Sci. 2010, 9, 846-853. [CrossRef] [PubMed] 
50. Arnanz, A.; Pintado-Sierra, M.; Corma, A.; Iglesias, M.; Sanchez, F. Bifunctional metal organic framework catalysts for multistep reactions: $\mathrm{MOF}-\mathrm{Cu}(\mathrm{BTC})-[\mathrm{Pd}]$ catalyst for one-pot heteroannulation of acetylenic compounds. Adv. Synth. Catal. 2012, 354, 1347-1355. [CrossRef]

51. Ferey, G.; Mellot-Draznieks, C.; Serre, C.; Millange, F.; Dutour, J.; Surble, S.; Margiolaki, I. A chromium terephthalate-based solid with unusually large pore volumes and surface area. Science 2005, 309, 2040-2042. [CrossRef] [PubMed]

52. Hu, Z.; Zhao, D. Metal-organic frameworks with Lewis acidity: Synthesis, characterization, and catalytic applications. CrystEngComm 2017, 19, 4066-4081. [CrossRef]

53. Chowdhury, P.; Bikkina, C.; Meister, D.; Dreisbach, F.; Gumma, S. Comparison of adsorption isotherms on $\mathrm{Cu}$-BTC metal organic frameworks synthesized from different routes. Microporous Mesoporous Mater. 2009, 117, 406-413. [CrossRef]

54. Peng, Y.; Krungleviciute, V.; Eryazici, I.; Hupp, J.T.; Farha, O.K.; Yildirim, T. Methane storage in metal-organic frameworks: Current records, surprise findings, and challenges. J. Am. Chem. Soc. 2013, 135, 11887-11894. [CrossRef] [PubMed]

55. Pérez-Mayoral, E.; Cĕjka, J. $\left[\mathrm{Cu}_{3}(\mathrm{BTC})_{2}\right]$ : A metal-organic framework catalyst for the friedländer reaction. ChemCatChem 2011, 3, 157-159. [CrossRef]

56. Yepez, R.; Garcia, S.; Schachat, P.; Sarnchez-Sarnchez, M.; Gonzarlez-Estefan, J.H.; Gonzarlez-Zamora, E.; Ibarra, I.A.; Aguilar-Pliego, J. Catalytic activity of HKUST-1 in the oxidation of trans-ferulic acid to vanillin. New J. Chem. 2015, 39, 5112-5115. [CrossRef]

57. Cavka, J.H.; Jakobsen, S.; Olsbye, U.; Guillou, N.; Lamberti, C.; Bordiga, S.; Lillerud, K.P. A new zirconium inorganic building brick forming metal organic frameworks with exceptional stability. J. Am. Chem. Soc. 2008, 130, 13850-13851. [CrossRef] [PubMed]

58. Chavan, S.; Vitillo, J.G.; Gianolio, D.; Zavorotynska, O.; Civalleri, B.; Jakobsen, S.; Nilsen, M.H.; Valenzano, L.; Lamberti, C.; Lillerud, K.P.; et al. $\mathrm{H}_{2}$ storage in isostructural UiO-67 and UiO-66 MOFs. Phys. Chem. Chem. Phys. 2012, 14, 1614-1626. [CrossRef] [PubMed]

59. Caratelli, C.; Hajek, J.; Cirujano, F.G.; Francesc, M.W.; Llabrés i Xamena, X.; Van Speybroeck, V. Nature of active sites on UiO-66 and beneficial influence of water in the catalysis of Fischer esterification. J. Catal. 2017, 352, 401-414. [CrossRef]

60. Cirujano, F.G.; Corma, A.; Llabrés, I.; Xamena, F.X. Zirconium-containing metal organic frameworks as solid acid catalysts for the esterification of free fatty acids: Synthesis of bio diesel and other compounds of interest. Catal. Today 2015, 257, 213-220. [CrossRef]

61. Phan, A.C.; Doonan, J.; Uribe-Romo, F.J.; Knobler, C.B.; O'Keeffe, M.; Yaghi, O.M. Synthesis, structure, and carbon dioxide capture properties of zeolitic imidazolate frameworks. Acc. Chem. Res. 2010, 43, 58-67. [CrossRef] [PubMed]

62. Yin, H.; Lee, T.; Choi, J.; Yip, A.C.K. On the zeolitic imidazolate framework-8 (ZIF-8) membrane for hydrogen separation from simulated biomass-derived syngas. Microporous Mesoporous Mater. 2016, 233, 70-77. [CrossRef]

63. Banerjee, R.; Phan, A.; Wang, B.; Knobler, C.; Furukawa, H.; O’Keeffe, M.; Yaghi, O.M. High-throughput synthesis of zeolitic imidazolate frameworks and application to $\mathrm{CO}_{2}$ capture. Science 2008, 319, 939-943. [CrossRef] [PubMed]

64. Gücüyener, C.; van den Bergh, J.; Gascon, J.; Kapteijn, F. Ethane/Ethene separation turned on its head: selective ethane adsorption on the metal-organic framework ZIF-7 through a gate-opening mechanism. J. Am. Chem. Soc. 2010, 132, 17704-17706. [CrossRef] [PubMed]

65. Kandiah, M.; Usseglio, S.; Svelle, S.; Olsbye, U.; Lillerud, K.P.; Tilset, M. Post-synthetic modification of the metal-organic framework compound UiO-66. J. Mater. Chem. 2010, 20, 9848-9851. [CrossRef]

66. Kaneti, Y.V.; Dutta, S.; Hossain, M.S.A.; Shiddiky, M.J.A.; Tung, K.L.; Shieh, F.K.; Tsung, C.K.; Wu, C.W.; Yamauchi, Y. Strategies for improving the functionality of zeolitic imidazolate frameworks: Tailoring nanoarchitectures for functional applications. Adv. Mater. 2017, 29, 1700213. [CrossRef] [PubMed]

67. Lu, X.; Wang, L.; Lu, X. Catalytic conversion of sugars to methyl lactate over Mg-MOF-74 in near-critical methanol solutions. Catal. Commun. 2018, 110, 23-27. [CrossRef]

68. Holm, M.S.; Pagán-Torres, Y.J.; Saravanamurugan, S.; Riisager, A.; Dumesic, J.A.; Taarning, E. Sn-beta catalysed conversion of hemicellulosic sugars. Green Chem. 2012, 14, 702-706. [CrossRef] 
69. Cabello, C.P.; Gómez-Pozuelo, G.; Opanasenko, M.; Nachtigall, P.; Čejka, J. Metal-organic frameworks M-MOF-74 and M-MIL-100: Comparison of textural, acidic, and catalytic properties. ChemPlusChem 2016, 81, 828-835. [CrossRef]

70. Holm, M.S.; Saravanamurugan, S.; Taarning, E. Conversion of sugars to lactic acid derivatives using heterogeneous zeotype catalysts. Science 2010, 328, 602-605. [CrossRef] [PubMed]

71. Murillo, B.; Zornoza, B.; Iglesia, O.; Téllez, C.; Coronas, J. Chemocatalysis of sugars to produce lactic acid derivatives on zeolitic imidazolate frameworks. J. Catal. 2016, 334, 60-67. [CrossRef]

72. Kruger, J.S.; Nikolakis, V.; Vlachos, D.G. Carbohydrate dehydration using porous catalysts. Curr. Opin. Chem. Eng. 2012, 1, 312-320. [CrossRef]

73. Timofeeva, M.N.; Panchenko, V.N.; Khan, N.A.; Hasan, Z.; Prosvirin, I.P.; Tsybulya, S.V.; Jhung, S.H. Isostructural metal-carboxylates MIL-100(M) and MIL-53(M.) (M.: V., Al, Fe and $\mathrm{Cr}$ ) as catalysts for condensation of glycerol with acetone. Appl. Catal. A. Gen. 2017, 529, 167-174. [CrossRef]

74. Zhang, B.; Hao, J.; Sha, Y.; Zhou, H.; Yang, K.; Song, Y.; Ban, Y.; He, R.; Liu, Q. Utilization of lignite derivatives to construct $\mathrm{Zr}$-based catalysts for the conversion of biomass-derived ethyl levulinate. Fuel 2018, 217, 122-130. [CrossRef]

75. Cirujano, F.G.; Corma, A.; Llabrés, I.; Xamena, F.X. Conversion of levulinic acid into chemicals: Synthesis of biomass derived levulinate esters over Zr-containing MOFs. Chem. Eng. Sci. 2015, 124, 52-60. [CrossRef]

76. Védrine, J.C. Heterogeneous catalysis on metal oxides. Catalysts 2017, 7, 341. [CrossRef]

77. Hu, Z.; Peng, Y.; Gao, Y.; Qian, Y.; Ying, S.; Yuan, D.; Horike, S.; Ogiwara, N.; Babarao, R.; Wang, Y.; et al. Direct synthesis of hierarchically porous metal-organic frameworks with high stability and strong Brønsted acidity: The decisive role of hafnium in efficient and selective fructose dehydration. Chem. Mater. 2016, 28, 2659-2667. [CrossRef]

78. Hu, Z.G.; Peng, Y.W.; Tan, K.M.; Zhao, D. Enhanced catalytic activity of a hierarchical porous metal-organic framework CuBTC. CrystEngComm 2015, 17, 7124-7129. [CrossRef]

79. Wee, L.H.; Lescouet, T.; Fritsch, J.; Bonino, F.; Rose, M.; Sui, Z.; Garrier, E.; Packet, D.; Bordiga, S.; Kaskel, S.; et al. Synthesis of monoglycerides by esterification of oleic acid with glycerol in heterogeneous catalytic process using tin-organic framework catalyst. Catal. Lett. 2013, 143, 356-363. [CrossRef]

80. Su, Y.; Chang, G.; Zhang, Z.; Xing, H.; Su, B.; Yang, Q.; Ren, Q.; Yang, Y.; Bao, Z. Catalytic dehydration of glucose to 5-hydroxymethylfurfural with a bifunctional metal-organic framework. AIChE J. 2016, 62, 4403-4417. [CrossRef]

81. Akiyama, G.; Matsuda, R.; Sato, H.; Takata, M.; Kitagawa, S. Cellulose hydrolysis by a new porous coordination polymer decorated with sulfonic acid functional groups. Adv. Mater. 2011, 23, $294-3297$. [CrossRef] [PubMed]

82. Herbst, A.; Janiak, C. Selective glucose conversion to 5-hydroxymethylfurfural (5-HMF) instead of levulinic acid with MIL-101Cr MOF-derivatives. New J. Chem. 2016, 40, 7958-7967. [CrossRef]

83. Liu, X.F.; Li, H.; Zhang, H.; Pan, H.; Huang, S.; Yang, K.L.; Yang, S. Efficient conversion of furfuryl alcohol to ethyl levulinate with sulfonic acid-functionalized MIL-101(Cr). RSC Adv. 2016, 6, 90232-90238. [CrossRef]

84. Jiang, J.; Yaghi, O.M. Brønsted acidity in metal-organic frameworks. Chem. Rev. 2015, 115, 6966-6997. [CrossRef] [PubMed]

85. Evans, J.D.; Sumby, C.J.; Doonan, C.J. Post-synthetic metalation of metal-organic frameworks. Chem. Soc. Rev. 2014, 43, 5933-5951. [CrossRef] [PubMed]

86. Juan-Alcanñiz, J.; Gascon, J.; Kapteijn, F. Metal-organic frameworks as scaffolds for the encapsulation of active species: State of the art and future perspectives. J. Mater. Chem. 2012, 22, 10102-10118. [CrossRef]

87. Chatterjee, A.; Hu, X.; FL-Yuk, L. A dual acidic hydrothermally stable MOF-composite for upgrading xylose to furfural. Appl. Catal. A Gen. 2018. [CrossRef]

88. Luan, Y.; Zheng, N.; Qi, Y.; Yu, J.; Wang, G. Development of a $\mathrm{SO}_{3} \mathrm{H}$-functionalized UiO-66 metal-organic framework by postsynthetic modification and studies of its catalytic activities. Eur. J. Inorg. Chem. 2014, 26, 4268-4272. [CrossRef]

89. Yabushita, M.; Li, P.; Islamoglu, T.; Kobayashi, H.; Fukuoka, A.; Farha, O.K.; Katz, A. Selective Metal-Organic Framework Catalysis of Glucose to 5-Hydroxymethylfurfural Using Phosphate-Modified NU-1000. Ind. Eng. Chem. Res. 2017, 56, 7141-7148. [CrossRef] 
90. Katz, M.J.; Mondloch, J.E.; Totten, R.K.; Park, J.K.; Nguyen, S.T.; Farha, O.K.; Hupp, J.T. Simple and compelling biomimetic metal-organic framework catalyst for the degradation of nerve agent simulants. Angew. Chem. Int. Ed. 2014, 53, 497-501. [CrossRef] [PubMed]

91. Liu, W.G.; Truhlar, D.G. Computational linker design for highly crystalline metal-organic framework NU-1000. Chem. Mater. 2017, 29, 8073-8081. [CrossRef]

92. Li, P.; Klet, R.C.; Moon, S.Y.; Wang, T.C.; Deria, P.; Peters, A.W.; Klahr, B.M.; Park, H.J.; Al-Juaid, S.S.; Hupp, J.T.; et al. Synthesis of nanocrystals of Zr-based metal-organic frameworks with csq-net: Significant enhancement in the degradation of a nerve agent simulant. Chem. Commun. 2015, 51, 10925-10928. [CrossRef] [PubMed]

93. Chatterjee, A.; Hu, X.; Lam, F.L.Y. Towards a recyclable MOF catalyst for efficient production of furfural. Catal. Today 2018, 314, 129-136. [CrossRef]

94. Chen, J.; Li, K.; Chen, L.; Liu, R.; Huang, X.; Ye, D. Conversion of fructose into 5-hydroxymethylfurfural catalyzed by recyclable sulfonic acid-functionalized metal-organic frameworks. Green Chem. 2014, 16, 2490-2499. [CrossRef]

95. Chiappe, C.; Rajamani, S. Synthesis of glycerol carbonate from glycerol and dimethyl carbonate in basic ionic liquids. Pure Appl. Chem. 2012, 84, 755-762. [CrossRef]

96. Climent, M.J.; Corma, A.; Frutos, P.D.; Iborra, S.; Noy, M.; Velty, A.; Concepción, P. Chemicals from biomass: Synthesis of GC by transesterification and carbonylation with urea with hydrotalcite catalysts. The role of acid-base pairs. J. Catal. 2010, 269, 140-149. [CrossRef]

97. Lee, S.D.; Park, G.A.; Kim, D.W.; Park, D.W. Catalytic performance of functionalized IRMOF-3 for the synthesis of glycerol carbonate from glycerol and urea. J. Nanosci. Nanotechnol. 2014, 14, 4551-4556. [CrossRef] [PubMed]

98. Xiang, W.; Zhang, Y.; Lin, H.; Liu, C.J. Nanoparticle/metal-organic framework composites for catalytic applications: Current status and perspective. Molecules 2017, 22, 2103. [CrossRef] [PubMed]

99. Yu, J.; Chao, M.; Yan, B.; Qin, X.; Shen, C.; Xue, H.; Pang, H. Nanoparticle/MOF composites: Preparations and applications. Mater. Horiz. 2017, 4, 557-569. [CrossRef]

100. Shen, K.; Chen, X.; Chen, J.; Li, Y. Development of MOF-derived carbon-based nanomaterials for efficient catalysis. ACS Catal. 2016, 6, 5887-5903. [CrossRef]

101. Li, P.; Zeng, H.C. Immobilization of metal-organic framework nanocrystals for advanced design of supported nanocatalysts. Appl. Mater. Interfaces 2016, 43, 29551-29564. [CrossRef] [PubMed]

102. Casas, N.; Schell, J.; Blom, R.; Maz, M. MOF and UiO-67/MCM-41 adsorbents for pre-combustion $\mathrm{CO}_{2}$ capture by PSA: Breakthrough experiments and process design. Sep. Purif. Technol. 2013, 111, $34-48$. [CrossRef]

103. Zhu, Q.L.; Qiang Xu, Q. Metal-organic framework composites. Chem. Soc. Rev. 2014, 43, 5468-5512. [CrossRef] [PubMed]

104. Yang, Q.; Xu, Q.; Jiang, H.L. Metal-organic frameworks meet metal nanoparticles: Synergistic effect for enhanced catalysis. Chem. Soc. Rev. 2017, 46, 4774-4808. [CrossRef] [PubMed]

105. Chen, L.; Huang, W.; Wang, X.; Chen, Z.; Yang, X.; Luque, R.; Li, Y. Catalytically active designer crown-jewel Pd-based nanostructures encapsulated in metal-organic frameworks. Chem. Commun. 2017, 53, 1184-1187. [CrossRef] [PubMed]

106. Juan-Alcanñiz, J.; Ramos-Fernandez, E.V.; Lafont, U.; Gascon, J.; Kapteijn, F. Building MOF bottles around phosphotungstic acid ships: One-pot synthesis of bifunctional polyoxometalate-MIL-101 catalysts. J. Catal. 2010, 269, 229-241. [CrossRef]

107. Juan-Alcanñiz, J.; Goesten, M.G.; Ramos-Fernandez, E.V.; Gascon, J.; Kapteijn, F. Towards efficient polyoxometalate encapsulationin MIL-100(Cr): Influence of synthesis conditions. New J. Chem. 2012, 36, 977-987. [CrossRef]

108. Wan, H.; Chen, C.; Wu, Z.; Que, Y.; Feng, Y.; Wang, W.; Liu, X. Encapsulation of Heteropolyanion-Based Ionic Liquid within the Metal-Organic Framework MIL-100(Fe) for Biodiesel Production. ChemCatChem 2015, 7, 441-449. [CrossRef]

109. Aijaz, A.; Zhu, Q.L.; Tsumori, N.; Akita, T.; Xu, Q. Surfactant-free Pd nanoparticles immobilized to a metal-organic framework with size- and location-dependent catalytic selectivity. Chem. Commun. 2015, 51, 2577-2580. [CrossRef] [PubMed] 
110. Maksimchuk, N.V.; Kholdeeva, O.A.; Kovalenko, K.A.; Fedin, V.P. MIL-101 supported polyoxometalates: Synthesis, characterization, and catalytic applications in selective liquid-phase oxidation. Isr. J. Chem. 2011, 51, 281-289. [CrossRef]

111. Ren, Y.; Wang, M.; Chen, X.; Yue, B.; He, H. Heterogeneous catalysis of polyoxometalate based organic-inorganic hybrids. Materials 2015, 8, 1545-1567. [CrossRef] [PubMed]

112. Bohre, A.; Dutta, S.; Saha, B. Upgrading furfurals to drop-in biofuels: An overview. ACS Sustain. Chem. Eng. 2015, 3, 1263-1277. [CrossRef]

113. Salomon, W.; Yazigi, F.J.; Roch-Marchal, C.; Mialane, P.; Horcajada, P.; Serre, C.; Haouas, M.; Taulelle, F.; Dolbecq, A. Immobilization of Co-containing polyoxometalates in MIL-101(Cr): Structural integrity versus chemical transformation. Dalton Trans. 2014, 43, 12698-12705. [CrossRef] [PubMed]

114. Song, J.; Luo, Z.; Britt, D.K.; Furukawa, H.; Yaghi, O.M.; Hardcastle, K.I.; Hill, C.L. A multiunit catalyst with synergistic stability and reactivity: A polyoxometalate metal organic framework for aerobic decontamination. J. Am. Chem. Soc. 2011, 133, 16839-16846. [CrossRef] [PubMed]

115. Zhao, J.; Anjali, J.; Yan, Y.; Lee, J.M. Cr-MIL-101-Encapsulated Keggin Phosphomolybdic Acid as a Catalyst for the One-Pot Synthesis of 2,5-Diformylfuran from Fructose. Chem CatChem 2017, 9, 1187-1191. [CrossRef]

116. Zhang, V.; Degirmenci, Y.; Li, C.; Hensen, E.J.M. Phosphotungstic Acid Encapsulated in Metal-Organic Framework as Catalysts for Carbohydrate Dehydration to 5-Hydroxymethylfurfural. ChemSusChem 2011, 4, 59-64. [CrossRef] [PubMed]

117. Chen, D.; Liang, F.; Feng, D.; Xian, M.; Zhang, H.; Liu, H.; Du, F. An efficient route from reproducible glucose to 5-hydroxymethylfurfural catalyzed by porous coordination polymer heterogeneous catalysts. Chem. Eng. J. 2016, 300, 177-184. [CrossRef]

118. Wee, L.H.; Bajpe, S.R.; anssens, N.; Hermans, I.; Kristof Houthoofd, K.; Kirschhock, C.E.A.; Johan, A.; Martens, J.A. Convenient synthesis of $\mathrm{Cu}_{3}(\mathrm{BTC})_{2}$ encapsulated Keggin heteropolyacid nanomaterial for application in catalysis. Chem. Commun. 2010, 46, 8186-8188. [CrossRef] [PubMed]

119. Bajpe, S.R.; Kirschhock, C.E.A.; Aerts, A.; Breynaert, E.; Absillis, G.; Parac-Vogt, T.N.; Giebeler, L.; Martens, J. Direct observation of molecular-level template action leading to self-assembly of a porous framework. Chem. Eur. J. 2010, 16, 3926-3932. [CrossRef] [PubMed]

120. Wang, Z.; Chen, Q. Conversion of 5-hydroxymethylfurfural into 5-ethoxymethylfurfural and ethyl levulinate catalyzed by MOF-based heteropolyacid materials. Green Chem. 2016, 18, 5884-5889. [CrossRef]

121. Zhu, J.; Wang, P.; Lu, M. Study on the one-pot oxidative esterification of glycerol with MOF supported polyoxometalates as catalyst. Catal. Sci. Technol. 2015, 5, 3383-3393. [CrossRef]

122. Guo, Q.; Ren, L.; Kumar, P.; Cybulskis, V.J.; Mkhoyan, M.K.A.; Davis, E.; Tsapatsis, M. A chromium Hydroxide/MIL-101(Cr) MOF composite catalyst and its use for the selective isomerization of glucose to fructose. Angew. Chem. Int. Ed. 2018, 57, 4926-4930. [CrossRef] [PubMed]

123. Luo, H.Y.; Lewis, J.D.; Roman-Leshkov, Y. Lewis acid zeolites for biomass conversion: Perspectives and challenges on reactivity, synthesis, and stability. Annu. Rev. Chem. Biomol. Eng. 2016, 7, 663-692. [CrossRef] [PubMed]

124. Wang, J.S.; Jin, F.Z.; Ma, H.C.; Li, X.B.; Liu, M.Y.; Kan, J.L.; Chen, G.J.; Dong, Y.B. Au@Cu(II)-MOF: Highly efficient bifunctional heterogeneous catalyst for successive oxidation-condensation reactions. Inorg. Chem. 2016, 55, 6685-6691. [CrossRef] [PubMed]

125. Zhao, M.; Yuan, K.; Wang, Y.; Li, G.D.; Gu, L.; Hu, W.P.; Zhao, H.J.; Tang, Z.Y. Metal-organic frameworks as selectivity regulators for hydrogenation reactions. Nature 2016, 539, 76-80. [CrossRef] [PubMed]

126. Fang, R.; Liu, H.; Luque, R.; Li, Y. Efficient and selective hydrogenation of biomass-derived furfural to cyclopentanone using Ru catalysts. Green Chem. 2015, 17, 4183-4188. [CrossRef]

127. Scognamiglio, J.; Jones, L.; Letizia, C.S.; Api, A.M. Fragrance material review on cyclopentanone. Food Chem. Toxicol. 2012, 50, S608-S612. [CrossRef] [PubMed]

128. Yin, D.; Ren, H.; Li, C.; Liu, J.; Liang, C. Highly selective hydrogenation of furfural to tetrahydrofurfuryl alcohol over MIL-101(Cr)-NH2 supported Pd catalyst at low temperature. Chin. J. Catal. 2018, 39, 319-326. [CrossRef]

129. Chen, J.; Liu, R.; Guo, Y.; Chen, L.; Gao, H. Selective hydrogenation of biomass-based 5-Hydroxymethylfurfural over catalyst of palladium immobilized on amine-functionalized metal-organic frameworks. ACS Catal. 2015, 5, 722-733. [CrossRef] 
130. Hester, P.; Xu, S.; Liang, W.; Al-Janabi, N.; Vakili, R.; Hill, P.; Muryn, C.A.; Chen, X.; Martin, P.A.; Fan, X. On thermal stability and catalytic reactivity of Zr-based metal-organic framework (UiO-67) encapsulated $\mathrm{Pt}$ catalysts. J. Catal. 2016, 340, 85-94. [CrossRef]

131. Lin, Z.; Cai, X.; Fu, Y.; Zhu, W.; Zhang, F. Cascade catalytic hydrogenation-cyclization of methyl levulinate to form g-valerolactone over Ru nanoparticles supported on a sulfonic acidfunctionalized UiO-66 catalyst. RSC Adv. 2017, 7, 44082-44088. [CrossRef]

132. Yang, J.; Ma, J.; Yuan, Q.; Zhang, P.; Guan, Y. Selective hydrogenation of furfural on Ru/Al-MIL-53: A comparative study on the effect of aromatic and aliphatic organic linkers. RSC Adv. 2016, 6, 92299-92304. [CrossRef]

133. Li, H.; Zhao, W.; Fang, Z. Hydrophobic Pd nanocatalysts for one-pot and high-yield production of liquid furanic biofuels at low temperatures. Appl. Catal. B Environ. 2017, 215, 18-27. [CrossRef]

134. Ning, L.; Liao, S.; Cui, H.; Yu, L.; Tong, X. Selective conversion of renewable furfural with ethanol to produce furan-2-acrolein mediated by Pt@MOF-5. ACS Sustain. Chem. Eng. 2018, 6, 135-142. [CrossRef]

135. Yuan, Q.; Zhan, D.; van Haandel, L.; Yea, F.; Xue, T.; Hensen, E.J.M.; Guan, Y. Selective liquid phase hydrogenation of furfural to furfuryl alcohol by Ru/Zr-MOFs. J. Mol. Catal. A Chem. 2015, 406, 58-64. [CrossRef]

136. Li, X.; Tjiptoputro, A.K.; Ding, J.; Xue, J.M.; Zhu, Y. Pd-Ce nanoparticles supported on functional Fe-MIL-101- $\mathrm{NH}_{2}$ : An efficient catalyst for selective glycerol oxidation. Catal. Today 2017, 279, 77-83. [CrossRef]

137. Chen, J.; Wang, S.; Huang, J.; Chen, L.; Ma, L.; Huang, X. Conversion of cellulose and cellobiose into sorbitol catalyzed by ruthenium supported on a polyoxometalate/metal-organic framework hybrid. ChemSusChem 2013, 6, 1545-1555. [CrossRef] [PubMed]

138. Chatterjee, A.; Hu, X.; Lam, F.L.Y. Catalytic activity of an economically sustainable fly-ash-metal-organic framework composite towards biomass valorization. Catal. Today 2018, 314, 137-146. [CrossRef]

139. Liu, X.W.; Sun, T.J.; Hu, S.D.; Wang, J.L. Composites of metal-organic frameworks and carbon-based materials: Preparations, functionalities and applications. J. Mater. Chem. A 2016, 4, 3584-3616. [CrossRef]

140. Canivet, J.; Fateeva, A.; Guo, Y.M.; Coasne, B.; Farrusseng, D. Water adsorption in MOFs: Fundamentals and applications. Chem. Soc. Rev. 2014, 43, 5594-5617. [CrossRef] [PubMed]

141. Liu, M.; Zhang, Y.; Zhu, E.; Jin, P.; Wang, K.; Zhao, J.; Li, C.; Yan, Y. Facile synthesis of halloysite nanotubes-supported acidic metal-organic frameworks with tunable acidity for efficient fructose dehydration to 5-Hydroxymethylfurfural. ChemistrySelect 2017, 2, 10413-10419. [CrossRef]

142. Guimarjes, L.; Enyashin, A.N.; Seifert, G.; Duarte, H.A. Structural, electronic, and mechanical properties of single-walled halloysite nanotube models. J. Phys. Chem. C 2010, 114, 11358-11363. [CrossRef]

143. Čelič, T.B.; Grilc, M.; Likozar, B.; Tušar, N.N. In-situ generation of Ni nanoparticles from metal-organic framework precursors and their use for biomass hydrodeoxygenation. ChemSusChem 2015, 8, 1703-1710. [CrossRef] [PubMed]

144. Insyani, R.; Verma, D.; Kim, S.M.; Kim, J. Direct one-pot conversion of monosaccharides into high-yield 2,5-dimethylfuran over a multifunctional Pd/Zr-based metal-organic framework@sulfonated graphene oxide catalyst. Green Chem. 2017, 19, 2482-2490. [CrossRef]

145. Yap, M.H.; Fow, K.L.; Chen, G.Z. Synthesis and applications of MOF-derived porous nanostructures. Green Energy Environ. 2017, 2, 218-245. [CrossRef]

146. Wang, Y.; Miao, Y.; Li, S.; Gao, L.; Xiao, G. Metal-organic frameworks derived bimetallic Cu-Co catalyst for efficient and selective hydrogenation of biomass-derived furfural to furfuryl alcohol. Mol. Catal. 2017, 436, 128-137. [CrossRef]

147. Fang, R.; Luque, R.; Li, Y. Selective aerobic oxidation of biomass-derived HMF to 2,5-diformylfuran using a MOF-derived magnetic hollow Fe-Co nanocatalyst. Green Chem. 2016, 18, 3152-3157. [CrossRef]

148. Fang, R.; Luque, R.; Li, Y. Efficient one-pot fructose to DFF conversion using sulfonated magnetically separable MOF-derived $\mathrm{Fe}_{3} \mathrm{O}_{4}$ (111) catalysts. Green Chem. 2017, 19, 647-655. [CrossRef]

149. Wang, Y.; Sang, S.; Zhu, W.; Gao, L.; Xiao, G. CuNi@C catalysts with high activity derived from metal-organic frameworks precursor for conversion of furfural to cyclopentanone. Chem. Eng. J. 2016, 299, 104-111. [CrossRef] 
150. Lai, H.K.; Chou, Y.Z.; Lee, M.H.; Lin, K.Y.A. Coordination polymer-derived cobalt nanoparticle-embedded carbon nanocomposite as a magnetic multi-functional catalyst for energy generation and biomass conversion. Chem. Eng. J. 2018, 332, 717-726. [CrossRef]

151. Jin, P.; Zhang, Y.; Chen, Y.; Pan, J.; Dai, X.; Liu, M.; Yan, Y.; Li, C. Facile synthesis of hierarchical porous catalysts for enhanced conversion of fructose to 5-hydroxymethylfurfural. J. Taiwan Inst. Chem. Eng. 2017, 75, 59-69. [CrossRef]

152. Grilc, M.; Likozar, B.; Levec, J. Hydrodeoxygenation and hydrocracking of solvolysed lignocellulosic biomass by oxide, reduced and sulphide form of NiMo, Ni, Mo and Pd catalysts. Appl. Catal. B 2014, 150-151, 275-287. [CrossRef]

153. Kong, P.S.; Aroua, M.K.; Daud, W.M.A.W. Conversion of crude and pure glycerol into derivatives: A feasibility evaluation. Renew. Sustain. Energy Rev. 2016, 63, 533-555. [CrossRef]

154. Massa, M.; Andersson, A.; Finocchio, E.; Busca, G. Gas-phase dehydration of glycerol to acrolein over $\mathrm{Al}_{2} \mathrm{O}_{3}{ }^{-}$, $\mathrm{SiO}_{2^{-}}$, and $\mathrm{TiO}_{2}$-supported $\mathrm{Nb}$ - and W.-oxide catalysts. J. Catal. 2013, 307, 170-184. [CrossRef]

155. Huang, L.; Qin, F.; Huang, Z.; Zhuang, Y.; Ma, J.; Xu, H.; Shen, W. Metal-organic framework mediated synthesis of small-sized $\gamma$-Alumina as a highly active catalyst for the dehydration of glycerol to acrolein. ChemCatChem 2018, 10, 381-386. [CrossRef]

156. Zhu, H.Y.; Riches, J.D.; Barry, J.C. $\gamma$-Alumina nanofibers prepared from aluminum hydrate with poly(ethylene oxide) surfactant. Chem. Mater. 2002, 14, 2086-2093. [CrossRef]

157. Shen, S.; Ng, W.K.; Chia, L.S.O.; Dong, R.; Tan, B.H. Morphology controllable synthesis of nanostructured boehmite and $\gamma$-Alumina by facile dry gel conversion. Cryst. Growth Des. 2012, 12, 4987-4994. [CrossRef]

158. Zheng, L.; Li, X.; Du, W.; Shi, D.; Ning, W.; Lu, X.; Hou, Z. Metal-organic framework derived Cu/ZnO catalysts for continuous hydrogenolysis of glycerol. Appl. Catal. B 2017, 203, 146-153. [CrossRef]

159. Loiseau, T.; Serre, C.; Huguenard, C.; Fink, G.; Taulelle, F.; Henry, M.; Bataille, T.; Férey, G. A rationale for the large breathing of the porous aluminum terephthalate (MIL-53) upon hydration. Chem. Eur. J. 2004, 10, 1373-1382. [CrossRef] [PubMed]

160. Ortiz, A.U.; Springuel-Huet, M.A.; Coudert, F.X.; Fuchs, A.H.; Boutin, A. Predicting Mixture Coadsorption in Soft Porous Crystals: Experimental and Theoretical Study of $\mathrm{CO}_{2} / \mathrm{CH}_{4}$ in MIL-53(Al). Langmuir 2012, 28, 494-498. [CrossRef] [PubMed]

161. Millange, F.; Serre, C.; Férey, G. Synthesis, structure determination and properties of MIL-53as and MIL-53ht: The first $\mathrm{Cr} \mathrm{r}^{\mathrm{III}}$ hybrid inorganic-organic microporous solids: $\mathrm{Cr}{ }^{\mathrm{III}}(\mathrm{OH}) \cdot\left\{\mathrm{O}_{2} \mathrm{C}-\mathrm{C}_{6} \mathrm{H}_{4}-\mathrm{CO}_{2}\right\} \cdot\left\{\mathrm{HO}_{2} \mathrm{C}-\mathrm{C}_{6} \mathrm{H}_{4}-\mathrm{CO}_{2} \mathrm{H}\right\}_{x}$. Chem. Commun. 2002, 822-823. [CrossRef]

162. Zi, G.; Yan, Z.; Wang, Y.; Chen, Y.; Guo, Y.; Yuan, F.; Gao, W.; Wang, Y.; Wang, J. Catalytic hydrothermal conversion of carboxymethyl cellulose to value-added chemicals over metal-organic framework MIL-53(Al). Carbohydr. Polym. 2015, 115, 146-151. [CrossRef] [PubMed]

163. Pérez-Ramirez, J.; Christensen, K.; Egeblad, C.H.; Christensen, C.H.; Groen, J.C. Hierarchical zeolites: Enhanced utilisation of microporous crystals in catalysis by advances in materials design. Chem. Soc. Rev. 2008, 37, 2530-2542. [CrossRef] [PubMed]

164. Wee, L.H.; Wiktor, C.; Turner, S.; Vanderlinden, W.; Janssens, N.; Bajpe, S.R.; Houthoofd, K.; Van Tendeloo, G.; De Feyter, S.; Kirschhock, C.E.A.; et al. Copper benzene tricarboxylate metal-organic framework with wide permanent mesopores stabilized by keggin polyoxometallate ions. J. Am. Chem. Soc. 2012, 134, 10911-10919. [CrossRef] [PubMed]

165. Cao, Y.; Ma, Y.; Wang, T.; Wang, X.; Huo, Q.; Liu, Y. Facile Fabricating Hierarchically Porous Metal-Organic Frameworks via a Template-Free Strategy. Cryst. Growth Des. 2016, 16, 504-510. [CrossRef]

166. Feng, L.; Yuan, S.; Zhang, L.L.; Tan, K.; Li, J.L.; Kirchon, A.; Liu, L.M.; Zhang, P.; Han, Y.; Chabal, Y.J.; Zhou, H.C. Creating hierarchical pores by controlled linker thermolysis in multivariate metal-organic frameworks. Am. Chem. Soc. 2018, 140, 2363-2372. [CrossRef] [PubMed]

167. Duan, C.; Li, F.; Zhang, H.; Li, J.; Wang, X.; Xi, H. Template synthesis of hierarchical porous metal-organic frameworks with tunable porosity. RSC Adv. 2017, 7, 52245-52251. [CrossRef]

168. Wee, L.H.; Meledina, M.; Turner, S.; Van Tendeloo, G.; Zhang, K.; Rodriguez-Albelo, L.M.; Masala, A.; Bordiga, S.; Jiang, J.; Navarro, J.A.R.; et al. 1D-2D-3D transformation synthesis of hierarchical metal-organic framework adsorbent for multicomponent alkane separation. J. Am. Chem. Soc. 2017, 139, 819-828. [CrossRef] [PubMed] 
169. Wee, L.H.; Lescouet, T.; Ethiraj, J.; Bonino, F.; Vidruk, E.; Garrier, E.; Packet, D.; Bordiga, S.; Farrusseng, D.; Herskowitz, M.; et al. Zeolitic Imidazolate Framework-8 Catalyst for Monoglyceride Synthesis. Chem CatChem 2013, 5, 3562-3566. [CrossRef]

170. Guan, H.Y.; LeBlanc, R.J.; Xie, S.Y.; Yue, Y. Recent progress in the syntheses of mesoporous metal-organic framework materials. Coord. Chem. Rev. 2018, 369, 76-90. [CrossRef]

171. Junggeburth, S.C.; Schwinghammer, K.; Virdi, K.S.; Scheu, C.; Lotsch, B.V. Towards Mesostructured Zinc Imidazolate Frameworks. Chem. Eur. J. 2012, 18, 2143-2152. [CrossRef] [PubMed]

172. Park, J.; Wang, Z.U.; Sun, L.B.; Chen, Y.P.; Zhou, H.C. Introduction of functionalized mesopores to metal-organic frameworks via metal-ligand-fragment coassembly. J. Am. Chem. Soc. 2012, 134, 20110-20116. [CrossRef] [PubMed]

173. McNamara, N.D.; Hicks, J.C. Chelating Agent-Free, Vapor-Assisted Crystallization Method to Synthesize Hierarchical Microporous/Mesoporous MIL-125 (Ti). ACS Appl. Mater. Interfaces 2015, 7, 5338-5346. [CrossRef] [PubMed]

174. Yabushita, M.; Li, P.; Bernales, V.; Kobayashi, H.; Fukuoka, A.; Gagliardi, L.; Farha, O.K.; Katz, A. Unprecedented selectivity in molecular recognition of carbohydrates by a metal-organic framework. Chem. Commun. 2016, 52, 7094-7097. [CrossRef] [PubMed]

175. Stavila, V.; Parthasarathi, R.; Davis, R.W.; El Gabaly, F.; Sale, K.L.; Simmons, B.A.; Singh, S.; Allendorf, M.D. MOF-Based Catalysts for Selective Hydrogenolysis of Carbon-Oxygen Ether Bonds. ACS Catal. 2016, 6, 55-59. [CrossRef]

176. Dhakshinamoorthy, A.; Garcia, H. Cascade Reactions Catalyzed by Metal Organic Frameworks. ChemSusChem 2014, 7, 2392-2410. [CrossRef] [PubMed]

177. Nandasiri, M.I.; Jambovane, S.R.; McGrail, B.P.; Schaef, H.T.; Nune, S.K. Adsorption, separation, and catalytic properties of densified metal-organic frameworks. Coord. Chem. Rev. 2016, 311, 38-52. [CrossRef]

(C) 2018 by the authors. Licensee MDPI, Basel, Switzerland. This article is an open access article distributed under the terms and conditions of the Creative Commons Attribution (CC BY) license (http:/ / creativecommons.org/licenses/by/4.0/). 